\title{
Impact of Freshwater Release in the North Atlantic under Different Climate Conditions in an OAGCM
}

\author{
DIDIER SWINGEDOUW \\ CERFACS, Toulouse, France \\ JULIETTE MignOT \\ LOCEAN/IPSL, UMR UPMC/CNRS/IRD/MNHN, Paris, France \\ Pascale Braconnot, Eloi Mosquet, and Masa Kageyama \\ LSCE/IPSL, UMR CEA/CNRS/UVSQ, Gif-sur-Yvette, France \\ RAMDANE ALKAMA \\ CNRM, Toulouse, France
}

(Manuscript received 13 January 2009, in final form 23 June 2009)

\begin{abstract}
The response of climate to freshwater input in the North Atlantic (NA) has raised a lot of concern about the issue of climate stability since the discovery of abrupt coolings during the last glacial period. Such coolings have usually been related to a weakening of the Atlantic meridional overturning circulation (AMOC), probably associated with massive iceberg surges or meltwater pulses. Additionally, the recent increase in greenhouse gases in the atmosphere has also raised the possibility of a melting of the Greenland ice sheet, which may impact the future AMOC, and thereby the climate. In this study, the extent to which the mean climate influences the freshwater release linked to ice sheet melting in the NA and the associated climatic response is explored. For this purpose the simulations of several climatic states [last interglacial, Last Glacial Maximum, mid-Holocene, preindustrial, and future $\left.\left(2 \times \mathrm{CO}_{2}\right)\right]$ are considered, and the climatic response to a freshwater input computed interactively according to a surface heat flux budget over the ice sheets is analyzed. It is shown that the AMOC response is not linear with the freshwater input and depends on the mean climate state. The climatic responses to these different AMOC changes share qualitative similarities for the general picture, notably a cooling in the Northern Hemisphere and a southward shift of the intertropical convergence zone (ITCZ) in the Atlantic and across the Panama Isthmus. The cooling in the Northern Hemisphere is related to the sea ice cover response, which strongly depends on the responses of the atmospheric circulation, the local oceanic heat transport, and the density threshold of the oceanic convection sites. These feedbacks and the magnitude of temperature and precipitation changes outside the North Atlantic depend on the mean climate.
\end{abstract}

\section{Introduction}

Massive discharges of freshwater or icebergs in the North Atlantic (NA) have occurred during several periods in the past. The most striking ones are the so-called Heinrich events (Heinrich 1988). They are recorded in the NA sediments by layers of ice-rafted debris, which

Corresponding author address: Didier Swingedouw, 42 Av. G. Coriolis, CERFACS, 31057 Toulouse, France.

E-mail: swingedo@cerfacs.fr indicate massive iceberg discharges during the last glacial period. The cause of such iceberg discharges remains unclear, but may be associated with the surging of the Laurentide ice sheet, potentially resulting from internal ice sheet instabilities (MacAyeal 1993) or external forcing (Bond and Lotti 1995). Freshwater input in the NA also seems to have occurred during interglacial periods, but with a lesser magnitude. For instance, the last interglacial (LIG; around $126 \mathrm{kyr}$ ago) is thought to have experienced a large decrease of the Greenland ice sheet (GIS) volume. Such a large amount of freshwater 
in the NA may have contributed to the sea level fluctuations by several meters (Cuffey and Marshall 2000; Otto-Bliesner et al. 2006). More recently, at $8.2 \mathrm{kyr}$ before present (BP), it has been hypothesized that around $1.63 \times 10^{14} \mathrm{~m}^{3}\left[5.2 \mathrm{~Sv} \mathrm{yr}^{-1}\left(1 \mathrm{~Sv} \equiv 10^{6} \mathrm{~m}^{3} \mathrm{~s}^{-1}\right)\right]$ of freshwater has been released in the NA within a few years through the discharge of Lakes Agassiz and Ojibway (Clarke et al. 2004). More generally, Bond et al. (2001) raised the possibility of repeated freshwater input during the Holocene of a lesser magnitude than an 8.2-kyr event and following a cycle of around $1500 \mathrm{yr}$. They hypothesized that these events could be associated with solar forcing fluctuations.

Such freshwater discharges diminish the sea surface salinity (SSS) in the NA, which contributes to stabilize the water column and potentially reduce the deep-water formation there. This reduction in deep-water formation is associated with two crucial processes. The first one [process (i)] is a weakening of the Atlantic meridional overturning circulation (AMOC), which reduces the northward heat transport in the NA; the second one [process (ii)] concerns the regional enhancement of the sea ice formation through the reduction in vertical heat exchange in the ocean interior (convection releases heat toward the surface ocean, which limits sea ice formation). Process (ii) is more regional, but it affects the surface radiative budget (through the high albedo of the sea ice), and therefore also the large-scale surface climate. These two processes are not independent from each other and are both related to the heat budget at the ocean surface. Both may cool the climate around the NA region, so that it has often been hypothesized that a cooling occurring at the same time as a freshwater discharge is likely to be related to a weakening of the AMOC as well as to changes in sea ice cover (Ganopolski and Rahmstorf 2001). Several modeling studies show that a freshwater discharge in the NA is indeed characterized by a large cooling in the NA (Manabe and Stouffer 1988; Schiller et al. 1997; Vellinga and Wood 2002). It is also associated with a slight warming in the Southern Hemisphere, as shown in ice sheet records of the last ice age (EPICA Community Members et al. 2006) and from ocean-atmosphere general circulation models (OAGCMs) or earth system models of intermediate complexity (EMICs), but with a lesser magnitude as compared to that of the data (Stocker 1998; Stouffer et al. 2006).

A meridional shift of the tropical precipitation patterns associated with freshwater discharges in the NA has also been recorded in paleodata (Peterson et al. 2000; Garcin et al. 2007; Stoll et al. 2007; Pahnke et al. 2007. Modeling studies (Stouffer et al. 2006) have shown that a large freshwater input in the NA under presentday conditions could lead to a southward shift of the intertropical convergence zone (ITCZ). Such changes can have important consequences for water supply in some tropical regions like the Sahel. A few studies have explored the mechanisms explaining the ITCZ shift under present-day conditions. According to Chiang et al. (2008), the leading mechanism is related to the buildup of an anomalous sea surface temperature (SST) dipole in the tropical Atlantic with a cooling north of the equator and a warming south of it. The origin of this dipole implies both the atmospheric response to the northern high-latitudes cooling and the oceanic adjustment to the weakening of convection in the NA (Wu et al. 2007). Using partially coupled experiments, Chiang and Bitz (2005) and Yang and Liu (2005) show that the cooling of the northern high latitudes propagates within a few years toward the equator through the interaction between winds (stronger northeasterly trades), evaporation, and SST [the subtropical wind-evaporation-sea surface temperature (WES) mechanism (Xie 1999)], which leads to a large cooling of the SST north of the equator. The ocean also adjusts to the collapse of the AMOC and the oceanic convection in the NA. This adjustment is made through Kelvin wave excitation (Kawase 1987). It leads to a deepening of the mixed layer in the entire tropics, and therefore to warmer SST there. Both processes (the meridional atmospheric bridge and the oceanic tunnel in the Atlantic) are probably involved in the development of an anomalous meridional surface temperature gradient (warming south of the equator, cooling north of it), which shifts the ITCZ southward in the Atlantic.

In addition, Xie et al. (2008) show how this shift of the ITCZ in the Atlantic propagates toward the Pacific through interactions between the surface temperature in the tropical Atlantic and the trade winds. This zonal atmospheric bridge across Central America leads to an anomalous SST dipole in the Pacific. Moreover, it has been hypothesized that the shift of the ITCZ increases the freshwater input into the entire Atlantic because the Andes partially block the moisture transport from the Atlantic to the Pacific. This effect would further decrease the AMOC, providing a positive feedback (Leduc et al. 2007). This mechanism is not supported by all OAGCM experiments (Vellinga et al. 2002; Krebs and Timmermann 2007), which show that it is not the freshwater forcing of the whole Atlantic that matters, but rather the increase in surface salinity north of the equator resulting from the ITCZ migration that leads to a stabilizing feedback for the AMOC.

The earth's surface temperature is very likely to increase in the coming decades in response to the increase in greenhouse gas concentration in the atmosphere (Solomon et al. 2007). Such a surface warming is likely to melt the GIS (Huybrechts and de Wolde 1999; Ridley et al. 2005; 
Charbit et al. 2008). The timing of such a melting is under debate, but ranges from centuries to millennia. It has been shown that for a fast GIS melting (total in less than a millennium), it can profoundly affect the AMOC and the climate of the NA (Fichefet et al. 2003; Swingedouw et al. 2006; Swingedouw et al. 2007a). Other studies find a weaker impact of the GIS melting for the AMOC (Ridley et al. 2005; Jungclaus et al. 2006; Mikolajewicz et al. 2007), so that the response of the AMOC to GIS melting still requires investigation.

A few studies have investigated possible links between the impact of a freshwater discharge and the mean climate state. They suggest that the sensitivity of the AMOC to freshwater discharge depends on the mean climate state. Using an EMIC, Ganopolski and Rahmstorf (2001) concluded that the AMOC is more sensitive to freshwater discharge in the NA during the last ice age than under present-day conditions. They argued that this is due to the different configuration of the convection sites under glacial climate, which are likely to be located south of the Greenland-IcelandScotland (GIS) Ridge, making them more sensitive to freshwater perturbation. It has also been argued that the closure of the Bering Strait can be a crucial factor for the sensitivity of the AMOC to freshwater input and its recovery from the freshwater discharge, because of its consequences for the spread of any SSS anomalies introduced in the NA (De Boer and Nof 2004; Hu et al. 2008). In addition, Bitz et al. (2007), using the Community Climate System Model, version 3 (CCSM3) OAGCM, show that the AMOC recovery following a freshwater input is slower under Last Glacial Maximum (LGM) conditions than that for modern climate. This collection of studies suggest that the mean climate state can therefore be very important for the AMOC response to a freshwater input, and more precisely that the AMOC is in a more stable state at present than during glacial periods.

To summarize, because of the large impact of freshwater discharges on the climate, it is important to evaluate the influence of the mean climate state and the external forcing on the climatic response to a freshwater perturbation in the NA.

In the present study we therefore propose to examine the following related questions:

- What is the relationship between the mean climate conditions and any potential freshwater input from the surrounding ice sheets in the NA?

- Is the response of the AMOC to freshwater discharge dependent on the mean climate state?

- Is the surface temperature and precipitation response to AMOC changes the same under different climate conditions?
To tackle these issues we propose to use the same OAGCM under different climatic periods and to compute the freshwater input in the NA, in order to evaluate the sensitivity of the response of the AMOC, NA, and global surface temperature and precipitation.

In the following section, we describe the experimental design used in this study. Then, we analyze the response of the AMOC (section 3). The surface temperature response is analyzed in section 4 and the precipitation response in section 5. Conclusions are presented in section 6 .

\section{Experimental design}

\section{a. Model description}

We use the L'Institut Pierre-Simon Laplace Coupled Model, version 4 (IPSL CM4) ocean-atmosphere-sea iceland coupled GCM (Marti et al. 2009). This state-of-the-art comprehensive OAGCM incorporates a global and local closure of the freshwater budget as described below. The model couples the Laboratoire de Météorologie Dynamique Zoom (LMDz; Hourdin et al. 2006) atmosphere general circulation model and the Océan Parallélisé (OPA; Madec et al. 1998) ocean general circulation model. A sea ice model (Fichefet and Maqueda 1997), which computes the ice thermodynamics and dynamics, is coupled with the ocean-atmosphere model. The atmospheric model is coupled to the Organizing Carbon and Hydrology in Dynamic Ecosystems (ORCHIDEE) land surface scheme (Krinner et al. 2005). The ocean and atmosphere exchange momentum, heat, and freshwater fluxes, and surface temperature and sea ice cover once a day, using the Ocean Atmosphere Sea Ice and Soil (OASIS) coupler (Valcke et al. 2004). None of these fluxes are corrected or adjusted. A complex river runoff scheme considers the water transport from land to the ocean. The model is run with a horizontal resolution of 96 points in longitude and 71 points in latitude $\left(3.7^{\circ} \times 2.5^{\circ}\right)$ for the atmosphere and 182 points in longitude and 149 points in latitude for the ocean, corresponding to an oceanic resolution of about $2^{\circ}$, with a higher latitudinal resolution of $0.5^{\circ}$ in the equatorial ocean. There are 19 vertical levels in the atmosphere and 31 levels in the ocean with the highest resolution $(10 \mathrm{~m})$ in the upper $150 \mathrm{~m}$.

In the ocean model, vertical eddy diffusivity and viscosity coefficients are computed from a level-1.5 turbulent closure scheme based on a prognostic equation for the turbulent kinetic energy (Blanke and Delecluse 1993). The Gent and Mc Williams (1990) parameterization, with a spatially varying coefficient, is used in order to represent the effects of mesoscale eddies on the transport of tracers 
and large-scale oceanic circulation. In locations with statically unstable stratification, a value of $100 \mathrm{~m}^{2} \mathrm{~s}^{-1}$ is assigned to the vertical eddy coefficients for momentum and tracers. A free surface is implemented (Roullet and Madec 2000), which ensures salt conservation.

The IPSL CM4 includes a parameterization of land ice melting through iceberg or direct runoff. This parameterization is based on thermodynamic laws, but does not incorporate any representation of the dynamics. The land ice areas and altitude are therefore fixed to their modern observed values. When the glacial surface is snow free and the surface temperature is greater than $0^{\circ} \mathrm{C}$, the surface temperature is set to $0^{\circ} \mathrm{C}$. The corresponding heat flux is used to melt the land ice, but the elevation and volume of the glaciers remain unchanged and no refreezing process is considered. The meltwater is routed to the ocean as a freshwater flux with a 10-yr average. Moreover, it is not directly distributed along the ice sheet, but uniformly over a wider region. The earth is divided into three latitude bands with limits at $90^{\circ} \mathrm{S}, 50^{\circ} \mathrm{S}, 40^{\circ} \mathrm{N}$, and $90^{\circ} \mathrm{N}$. For the melting taking place in the northern band, the freshwater is sent to the Atlantic and the Nordic seas, but not to the Pacific (see Marti et al. 2009 for details). This parameterization is switched on or off in most of our experiments, while in one of them a given freshwater flux is directly imposed in a smaller region in the NA.

\section{b. Numerical experiments}

Five pairs of simulations lasting for at least $250 \mathrm{yr}$ have been performed using the IPSL CM4. Each pair is composed of a "control" simulation under given climatic conditions and a "hosing" simulation where additional freshwater input is added in the NA. The different experiments are summarized in Table 1 . The pairs of simulations differ by the baseline climates that they represent and thus they allow exploration of the impact of an anomalous freshwater flux under such different baseline climates. As explained above, in all but one pair of simulations, this additional freshwater input is related to the ice sheet parameterization. The different climatic periods considered are the LIG, at $126 \mathrm{kyr}$ BP (experiments are termed LIGc for the "control" simulation and LIGh for the "hosing" simulation); the LGM, at $21 \mathrm{kyr}$ BP (control and hosing simulation experiments are, respectively, LGMc and LGMh); the mid-Holocene period (HOL), at 6 kyr BP (control and hosing simulation experiments are, respectively, HOLc and HOLh); the preindustrial period (PRE), corresponding to the climatic conditions around 1860 (control and hosing simulation experiments are, respectively, PREc and PREh); and a "future" (FUT) climate pro- jection (control and hosing simulation experiments are, respectively, FUTc and FUTh).

Differences in the mean simulated climates arise from the orbital configuration (Berger 1978), the atmospheric concentration of the major trace gases, and the size and extent of the ice sheets (see Table 2). In the LIG and HOL experiments, because of the changes in orbital forcing, the seasonal cycle of insolation is enhanced in the Northern Hemisphere (up to more than $60 \mathrm{~W} \mathrm{~m}^{-2}$ in summer around the North Pole in LIG) and reduced in the Southern Hemisphere (Fig. 1). Both the HOL and LGM simulations follow the experimental design of the Paleoclimate Modeling Intercomparison Project (PMIP; Braconnot et al. 2007; see information online at http:// pmip2.lsce.ipsl.fr). The experimental design of the LGM experiments accounts for the presence of the large ice sheets in the Northern Hemisphere, the lower sea level, and the reduction of the trace gas concentration in the atmosphere. For the future climate projection (FUT), we consider an idealized $1 \% \mathrm{yr}^{-1}$ increase in $\mathrm{CO}_{2}$ following the CMIPs protocol (Meehl et al. 2000). It starts from preindustrial conditions, and the atmospheric $\mathrm{CO}_{2}$ concentration increases by $1 \% \mathrm{yr}^{-1}$ over $70 \mathrm{yr}$, increasing from 280 up to $560 \mathrm{ppm}$; it is then kept constant at $560 \mathrm{ppm}$.

Because they are computed interactively through the heat flux budget over land ice areas and routed in the Atlantic north of $40^{\circ} \mathrm{N}$ as in Swingedouw et al. (2007a, see above) in all experiments except PREh, the freshwater inputs in the hosing experiments are not the same and depend on the climatic conditions (Table 1). For the control experiments of FUT, HOL, and LIG, the freshwater flux computed from the energy budget on the ice sheets is not released to the NA, while it is released in the hosing experiments. For the LGMc simulation, the experimental setup is slightly different. The freshwater flux from potentially melting ice sheets is not computed. In fact, as snow accumulates on the ice sheets, the excess snow has to be delivered back to the ocean in order for it not to drift. This is performed using the same zones as for the freshwater fluxes in the other experiments. In particular, for the Laurentide and Fennoscandian ice sheets excess snow is delivered to the North Atlantic and Arctic Oceans (north of $40^{\circ} \mathrm{N}$ ). For LGMh, we have doubled the freshwater input from the excess snow accumulating on the ice sheets (Kageyama et al. 2009). The freshwater is therefore not conserved in this simulation, while it is conserved in LGMc. Concerning PREc, this simulation includes the parameterization of the land ice melting, but the corresponding melting represents less than $10 \mathrm{mSv}$ for the preindustrial conditions. We have thus conducted a traditional hosing experiment (PREh) with an additional $0.1 \mathrm{~Sv}$ of freshwater input in 
TABLE 1. Description of the numerical experiments performed. All of these experiments are integrated for (at least) $250 \mathrm{yr}$. The columns describe successively the name of each simulation, the corresponding epoch, the initial conditions for the ocean and atmosphere, the type of freshwater hosing, and the main references that already describes the simulation. In the hosing column, two regions are considered depending on where the freshwater is put: north of $40^{\circ} \mathrm{N}$ in NA and Arctic $\left(>40^{\circ} \mathrm{N}\right)$ and between $50^{\circ}$ and $70^{\circ} \mathrm{N}$ in the NA $\left(50^{\circ}-\right.$ $70^{\circ} \mathrm{N}$ ). This column also sums up the way the freshwater is computed (see the text for more details).

\begin{tabular}{lclll}
\hline \hline Name & Epoch & \multicolumn{1}{c}{ Initial conditions } & \multicolumn{1}{c}{ Hosing } & Reference \\
\hline LIGc & $126 \mathrm{kyr} \mathrm{BP}$ & Levitus (1982) and arbitrary 1 Jan & No & Braconnot et al. (2008) \\
LIGh & $126 \mathrm{kyr} \mathrm{BP}$ & Levitus (1982) and arbitrary 1 Jan & Ice sheet melting: $>40^{\circ} \mathrm{N}$ & Braconnot et al. (2008) \\
LGMc & $21 \mathrm{kyr} \mathrm{BP}$ & 150-yr spinup under LGM conditions & No & Kageyama et al. (2009) \\
LGMh & $21 \mathrm{kyr} \mathrm{BP}$ & 150-yr spinup under LGM conditions & Accumulation $\times 2:>40^{\circ} \mathrm{N}$ & Kageyama et al. (2009) \\
HOLc & $6 \mathrm{kyr} \mathrm{BP}$ & Levitus (1982) and arbitrary 1 Jan & No & Braconnot et al. (2007) \\
HOLh & $6 \mathrm{kyr} \mathrm{BP}$ & Levitus (1982) and arbitrary 1 Jan & Ice sheet melting: $>40^{\circ} \mathrm{N}$ & Braconnot et al. (2007) \\
PREc & 1860 & 200-yr spinup under preindustrial conditions & No & Swingedouw et al. (2007b) \\
PREh & 1860 & 200-yr spinup under preindustrial conditions & Heaviside of 0.1 Sv: $50-70^{\circ} \mathrm{N}$ & none \\
FUTc & $2 \times \mathrm{CO}_{2}$ & 200-yr spinup under preindustrial conditions & No & Swingedouw et al. (2007a) \\
FUTh & $2 \times \mathrm{CO}_{2}$ & 200-yr spinup under preindustrial conditions & Ice sheet melting: $>40^{\circ} \mathrm{N}$ & Swingedouw et al. (2007a) \\
\hline
\end{tabular}

the NA between $50^{\circ}$ and $70^{\circ} \mathrm{N}$, as in Stouffer et al. (2006), but lasting for $250 \mathrm{yr}$.

The regions where the freshwater input is added are therefore different between PREh and the other experiments (LIGh, HOLh, LGMh, and FUTh). This was done to allow for a direct comparison with the coordinated experiments of Stouffer et al. (2006). The region of freshwater release in PREh is more centered on the convection sites than for the others $\left(50^{\circ}-70^{\circ} \mathrm{N}\right.$, as compared to $40^{\circ}-90^{\circ} \mathrm{N}$ in the Atlantic and Arctic) so that the effect of the freshwater input could be larger. Nevertheless, as shown in Stouffer et al. (2006), the limited size of the region affected by freshwater perturbation can allow the convection sites to move out of this region, which may not be the case with the larger freshwater input zone north of $40^{\circ} \mathrm{N}$. It is thus quite difficult to evaluate the exact impact of the difference in freshwater input location. This needs to be kept in mind however when comparing PREh with the other hosing simulations.

Thus, the experimental design for the hosing experiments is not rigorously similar for the different climates. Indeed, this study was not designed to be a coordinated intercomparison at first. Rather, we took the opportunity of different existing simulations to isolate robust processes at play in the different background climates. To our knowledge, IPSL CM4 is the first state-of-the-art coupled OAGCM with all of these simulations available.

\section{c. Descriptions of the control simulations}

The climate that is simulated in the control experiments under the different climatic forcing exhibits large differences in terms of global mean temperature and precipitation (Table 3). These differences reach $7.1^{\circ} \mathrm{C}$ for the global temperature and $0.37 \mathrm{~mm} \mathrm{day}^{-1}$ for the global precipitation between FUTc and LGMc. The strongest AMOC is simulated for LGMc (Fig. 2 and Table 3). This is not in agreement with paleoceanographic reconstructions (Duplessy et al. 1988; McManus et al. 2004; Lynch-Stieglitz et al. 2007), which evaluate the AMOC to be weaker than that under present-day conditions. This is nonetheless a traditional bias of OAGCM simulations, as reported in Weber et al. (2007). Another bias of this model concerns the magnitude of the AMOC in PREh that is not strong enough because of an excess of precipitation in the NA and a weak gyre salinity transport in the NA, which both lead to a fresh bias in salinity in the NA and to a lack of convection in the Labrador Sea (Swingedouw et al. 2007b). As a consequence, the northward oceanic heat transport in the Atlantic is weaker than observation-based estimates (Table 3). This is an important caveat of the present study that has to be kept in mind. This study therefore has to be taken only as a sensitivity analysis of the impact of different freshwater input in the NA under different

TABLE 2. Orbital parameter and trace gases for the different climates considered.

\begin{tabular}{|c|c|c|c|c|c|c|}
\hline Epoch & $\mathrm{CO}_{2}$ (ppmv) & $\begin{array}{l}\text { Trace gases } \\
\mathrm{N}_{2} \mathrm{O}(\text { ppbv) }\end{array}$ & $\mathrm{CH}_{4}$ (ppbv) & Eccentricity & $\begin{array}{c}\text { Orbital parameters } \\
\text { Obliquity }\left(^{\circ}\right)\end{array}$ & Perihelion $\left({ }^{\circ}\right)$ \\
\hline LIG & 280 & 270 & 650 & 0.0397 & 23.928 & 291.24 \\
\hline LGM & 185 & 200 & 350 & 0.0190 & 22.949 & 114.42 \\
\hline HOL & 280 & 270 & 650 & 0.0187 & 24.105 & 0.87 \\
\hline PRE & 280 & 290 & 700 & 0.0167 & 23.446 & 102.04 \\
\hline FUT & 560 & 290 & 700 & 0.0167 & 23.446 & 102.04 \\
\hline
\end{tabular}




\section{a) PRE}

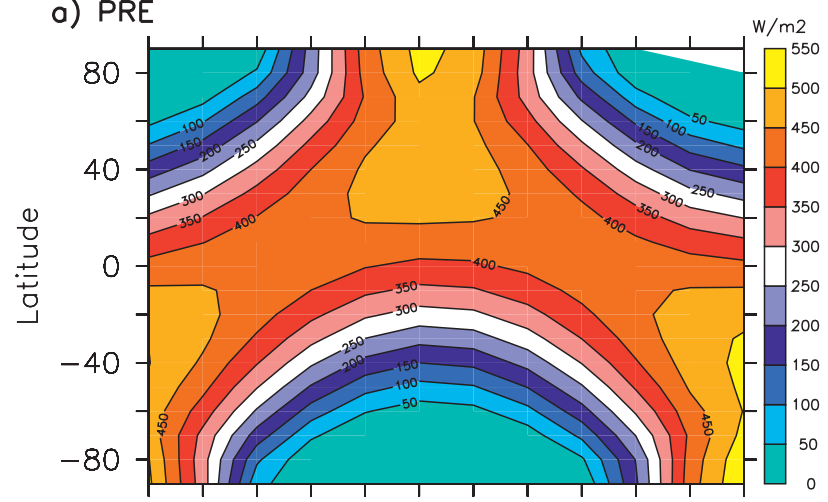

c) LGM-PRE

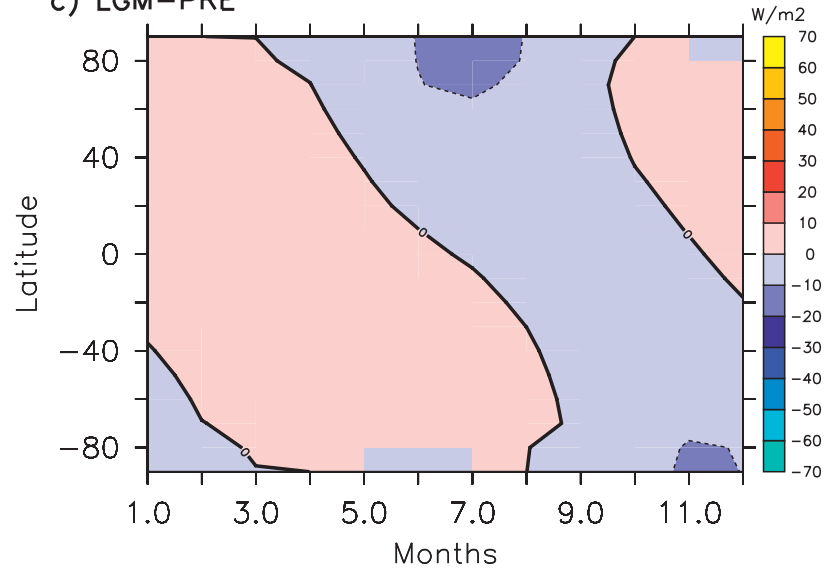

b) HOL-PRE

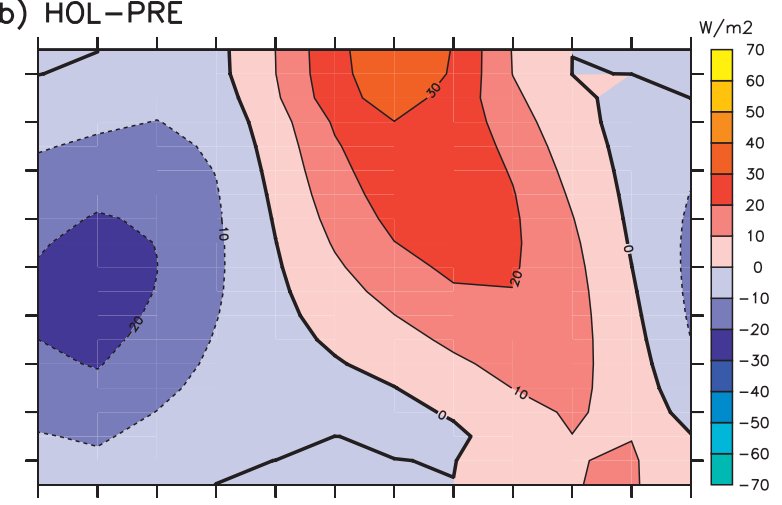

d) LIG-PRE

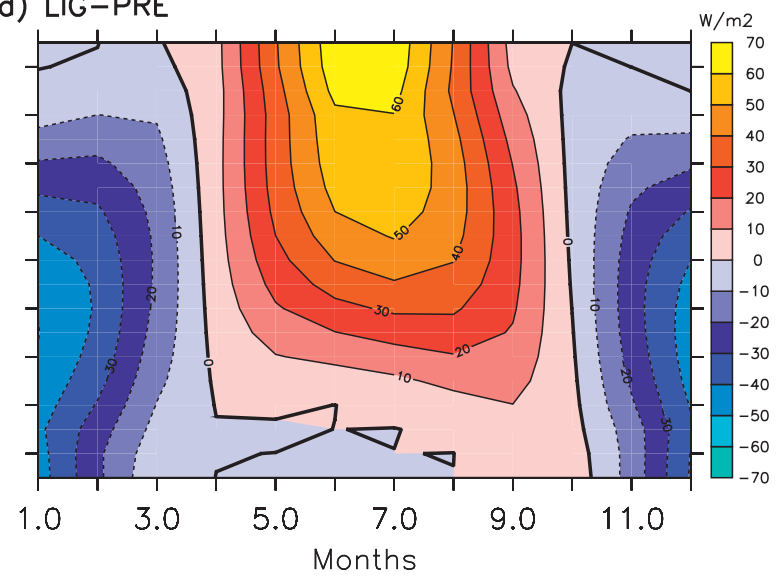

FIG. 1. Insolation $\left(\mathrm{W} \mathrm{m}^{-2}\right.$ ) as a function of latitude and months for (a) PRE. Anomalies of insolation as compared to PRE for (b) HOL, (c) LGM, and (d) LI. The contour interval is $50 \mathrm{~W} \mathrm{~m}^{-3}$ in (a) and $10 \mathrm{~W} \mathrm{~m}^{-3}$ in (b)-(d).

climate conditions. The AMOC is slightly enhanced in HOLc and LIGc climate conditions as compared to PREc, while FUTc is slightly weaker (Table 3), because of the surface stratification resulting from the warming. These differences between the control simulations also appear in terms of convection site patterns. Figure 3 (left column) shows that the mixed layer in winter is deeper in most of the NA in LIGc, LGMc, and HOLc as compared to PREc, while it is shallower in FUTc. This is attributed to slight differences in heat and freshwater forcings, the analysis of which is beyond the scope of this study.

From Fig. 4 it can be seen that none of the control experiments exhibits any large drift for the AMOC. This is true in particular for LIGc and HOLc, although these simulations start from Levitus (1982, see Table 1). Indeed, the changes in annual mean radiative forcing are weak, so that the global temperature and salinity drifts in these simulations are similar to that of PREc $(0.028$ $\mathrm{K}_{\text {century }}{ }^{-1}$ and -0.003 PSU century ${ }^{-1}$, respectively). Note that HOLc was continued for another $500 \mathrm{yr}$ and that all the seasonal characteristics of the simulated climate remain similar to the one obtained after $200 \mathrm{yr}$ of simulation.

\section{Freshwater input and $\mathrm{AMOC}$ changes}

The anomalous freshwater volume accumulated over the $250 \mathrm{yr}$ of the different hosing experiments is presented in the first column of Fig. 5. This freshwater input volume amounts to about $8 \times 10^{14} \mathrm{~m}^{3}$, which represents about one-third of the present-day GIS volume. It varies from $7.3 \times 10^{14} \mathrm{~m}^{3}(\mathrm{HOLh})$ to $13.6 \times 10^{14} \mathrm{~m}^{3}(\mathrm{LIGh})$. The computed freshwater input in FUTh is 0.58 times lower than that in LIGh, which is interesting because the GIS seems to have remained during the LIG, even though it has a reduced extent and altitude (North Greenland Ice Core Project Members 2004). Because the melting of the GIS in LIGh represents more than half its volume in $250 \mathrm{yr}$, this suggests that a stabilizing effect (not represented here, like the refreezing process, e.g.) has played a role to limit this melting at that time. This flux therefore represents an upper bound of the melting during the LIG. 
TABLE 3. Key characteristics of the different climates analyzed, averaged over the first $250 \mathrm{yr}$ of each control simulation (listed in Table 1) \pm the standard deviations for the interannual variability over the $250 \mathrm{yr}$ of simulation. Note that for the sea ice area, the LGM land-sea mask is different from the others because of large changes in sea level and the presence of large glaciers (in the Barents Sea, e.g.). This leads to a difference in sea area of $8.0 \times 10^{12} \mathrm{~m}^{2}$ between LGM and the other experiments in the Northern Hemisphere and $1.6 \times$ $10^{12} \mathrm{~m}^{2}$ in the Southern Hemisphere. The last column gives observation-based estimates for each variables coming from the 40-yr European Centre for Medium-Range Weather Forecasts (ECMWF) Re-Analysis (ERA-40; Uppala et al. 2005), Global Precipitation Climatology Project (GPCP; Adler et al. 2003), Hadley Centre Global Sea Ice and Sea Surface Temperature (HadISST; Rayner et al. 2003), Ganachaud and Wunsch (2000; GW2000), and Talley et al. (2003; T2003). Note that the climate of PREc has different boundary conditions than for present-day conditions, which partly explains the fact that it is cooler.

\begin{tabular}{|c|c|c|c|c|c|c|}
\hline & INTc & LGMc & HOLc & PREc & FUTc & Obs \\
\hline Global temperature $\left({ }^{\circ} \mathrm{C}\right)$ & $12.9 \pm 0.25$ & $8.9 \pm 0.11$ & $12.8 \pm 0.27$ & $12.8 \pm 0.13$ & $16.0 \pm 0.22$ & $15.2 \pm 0.17($ ERA-40) \\
\hline Global precipitation $\left(\mathrm{mm} \mathrm{day}{ }^{-1}\right)$ & $2.60 \pm 0.02$ & $2.39 \pm 0.01$ & $2.59 \pm 0.02$ & $2.59 \pm 0.01$ & $2.76 \pm 0.02$ & $2.65 \pm 0.07(\mathrm{GPCP})$ \\
\hline Northern sea ice area $\left(10^{12} \mathrm{~m}^{2}\right)$ & $9.1 \pm 0.33$ & $7.8 \pm 0.10$ & $9.7 \pm 0.33$ & $10.5 \pm 0.29$ & $5.5 \pm 0.59$ & $10.7 \pm 0.38(\mathrm{HadISST})$ \\
\hline Southern sea ice area $\left(10^{12} \mathrm{~m}^{2}\right)$ & $7.0 \pm 0.57$ & $9.6 \pm 0.70$ & $7.0 \pm 0.56$ & $7.7 \pm 0.47$ & $4.1 \pm 0.67$ & $9.87 \pm 0.38(\mathrm{HadISST})$ \\
\hline Temperature $>25^{\circ} \mathrm{N}\left({ }^{\circ} \mathrm{C}\right)$ & $4.9 \pm 0.31$ & $-3.3 \pm 0.18$ & $4.5 \pm 0.32$ & $4.0 \pm 0.20$ & $8.6 \pm 0.34$ & $8.5 \pm 0.25($ ERA- 40$)$ \\
\hline Ocean $\mathrm{HT}\left(25^{\circ} \mathrm{N}\right.$ in $\left.\mathrm{PW}\right)$ & $1.36 \pm 0.12$ & $1.27 \pm 0.11$ & $1.28 \pm 0.14$ & $1.21 \pm 0.14$ & $1.22 \pm 0.14$ & $1.8 \pm 0.3(\mathrm{GW} 2000)$ \\
\hline Atm. HT $\left(25^{\circ} \mathrm{N}\right.$ in PW $)$ & $3.8 \pm 0.11$ & $4.13 \pm 0.12$ & $3.85 \pm 0.12$ & $3.99 \pm 0.11$ & $3.98 \pm 0.11$ & $3.16 \pm 0.3($ ERA-40) \\
\hline Atl. HT $\left(25^{\circ} \mathrm{N}, \mathrm{PW}\right)$ & $0.8 \pm 0.07$ & $0.89 \pm 0.06$ & $0.77 \pm 0.07$ & $0.68 \pm 0.06$ & $0.69 \pm 0.07$ & $1.3 \pm 0.3(\mathrm{GW} 2000)$ \\
\hline AMOC maximum (Sv) & $12.8 \pm 1.49$ & $14.4 \pm 0.58$ & $12.5 \pm 1.26$ & $11.0 \pm 0.51$ & $10.0 \pm 0.60$ & $18 \pm 5(\mathrm{~T} 2003)$ \\
\hline $\mathrm{AMOC} 25^{\circ} \mathrm{N}(\mathrm{Sv})$ & $11.9 \pm 1.37$ & $13.3 \pm 0.94$ & $10.9 \pm 1.23$ & $9.7 \pm 0.68$ & $8.8 \pm 0.85$ & $17 \pm 4(\mathrm{GW} 2000)$ \\
\hline
\end{tabular}

The weakening of the AMOC after one century of freshwater forcing in PREh (Fig. 4) allows a comparison of the sensitivity of the IPSL CM4 with the one considered by Stouffer et al. (2006). The AMOC is reduced by $4.2 \mathrm{~Sv}$ (or a $40 \%$ reduction) after $100 \mathrm{yr}$ as compared to PREc (Fig. 4). This is to be compared with the $5.6 \mathrm{~Sv}$ (responses going from around 1 to $10 \mathrm{~Sv}$ ) reported for the ensemble mean of Stouffer et al. (2006) after $100 \mathrm{yr}$ (representing a $30 \%$ reduction, with responses going from around $5 \%$ to $60 \%$ ). Our model therefore exhibits a similar sensitivity to freshwater input as most of stateof-the-art OAGCMs in transient phase.

After $250 \mathrm{yr}$ of freshwater input in the NA, the AMOC has weakened under all climatic conditions (Fig. 2, right panels, and Fig. 4). The comparison of the different simulations suggests that the decrease of the AMOC maximum is nonlinear with freshwater input volume after $250 \mathrm{yr}$. In particular, the weakening of the AMOC in LGMh is very large with respect to the freshwater perturbation, as compared to HOLh, for instance, for which the freshwater perturbation is lower than that for LGMh. Figure 2d shows that one can hardly speak of "overturning" and "interhemispheric transport" at the end of LGMh. The AMOC can thus be considered as being practically "off." For FUTh, Fig. 3j shows that after $250 \mathrm{yr}$ of forcing, the mixed layer depth in the area of deep convection does not exceed $300 \mathrm{~m}$. Thus, although Fig. 2j still shows a large-scale overturning pattern, it is associated with shallow- to intermediate-depth ventilation rather than deep-water formation. In LIGh, HOLh, and PREh, final mixed layers are shallower than in the corresponding control states, but they still exceed $800 \mathrm{~m}$ (Figs. 3b,f,h). Accordingly, the AMOC (Figs.
$2 \mathrm{~b}, \mathrm{f}, \mathrm{h})$ maximum is weaker than in the corresponding control experiment, but it still corresponds to a largescale interhemispheric overturning. Note that its width has decreased in all three simulations as compared to the control climate and that the deep AABW cell is thicker. However, it is not stronger.

These results show that the AMOC response to freshwater input is sensitive to the mean climate conditions. The larger sensitivity of the AMOC in LGMh as compared to interglacial conditions is in agreement with previous studies (Ganopolski and Rahmstorf 2001). We will not further analyze these different sensitivities of the AMOC, and the rest of this study focuses on the climatic response to a freshwater input in the NA.

\section{Temperature response}

The response of the mean surface air temperature to the 250-yr freshwater input is displayed in Fig. 6. In all of the simulations, the general picture is a surface cooling in the Northern Hemisphere (spatial average going from $0.19^{\circ} \mathrm{C}$ in HOLh to $0.78^{\circ} \mathrm{C}$ in FUTh for the last $30 \mathrm{yr}$ of each pair), and a slight warming in the Southern Hemisphere (spatial average going from $0.02^{\circ} \mathrm{C}$ in LGMh to $0.25^{\circ} \mathrm{C}$ in LIGh for the last $30 \mathrm{yr}$ of each pair), which qualitatively follows the traditional seesaw pattern of the surface temperature response to an AMOC collapse (e.g., Vellinga and Wood 2002; Stouffer et al. 2006). However, an unusual warming appears on the eastern coast of Greenland north of $60^{\circ} \mathrm{N}$ in all experiments but LGMh. This feature is particularly developed in HOLh and LIGh, but the mean temperature response averaged north of $25^{\circ} \mathrm{N}$ is indeed a cooling for all experiments (Fig. 7d). 


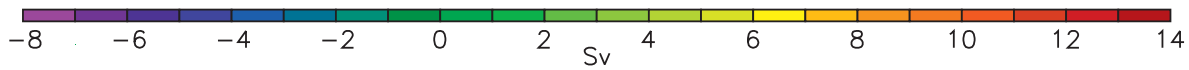

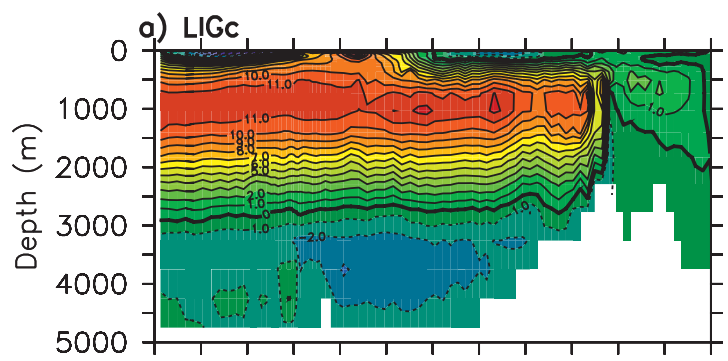

b) LIGh
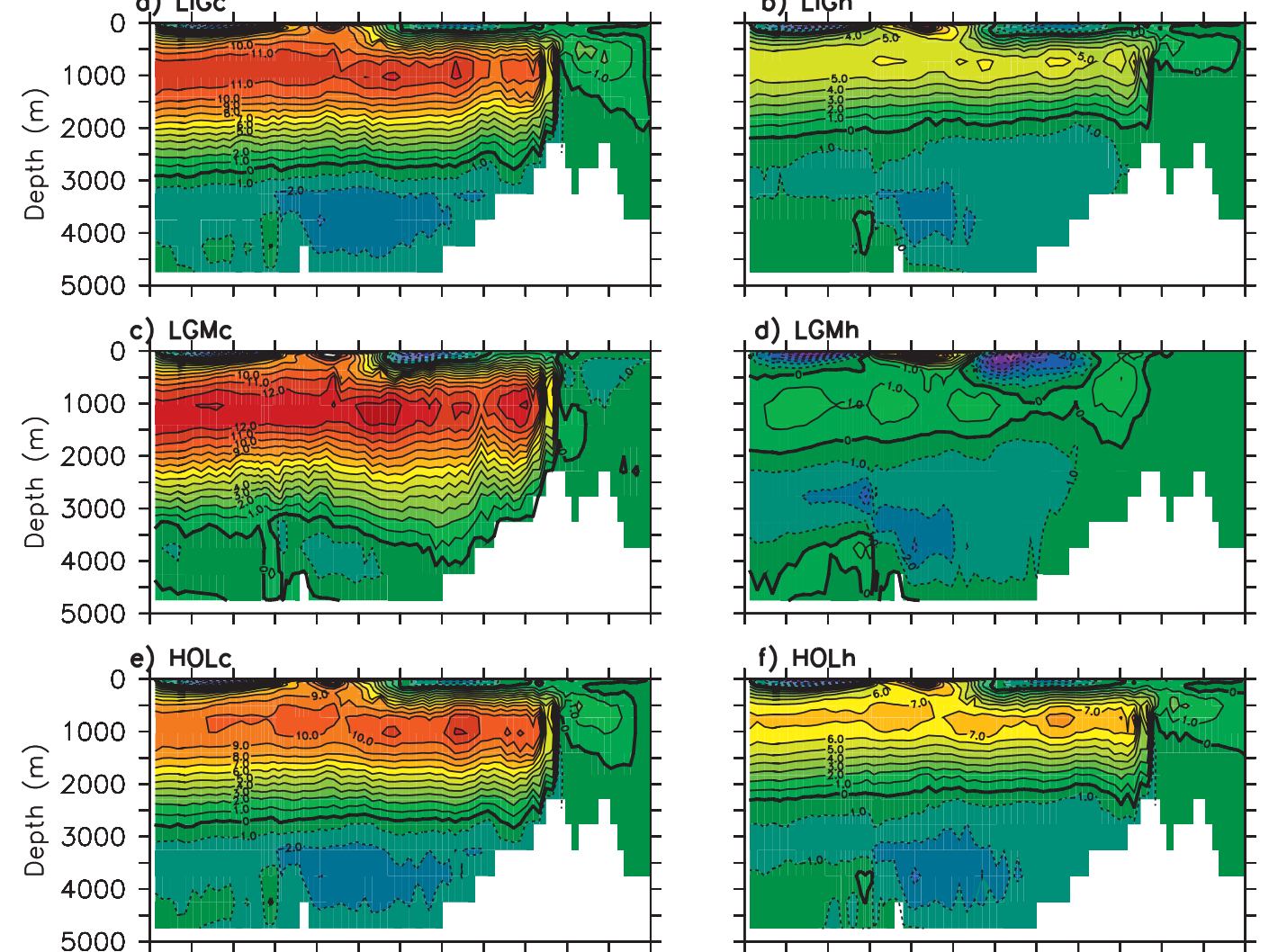

f) HOLh
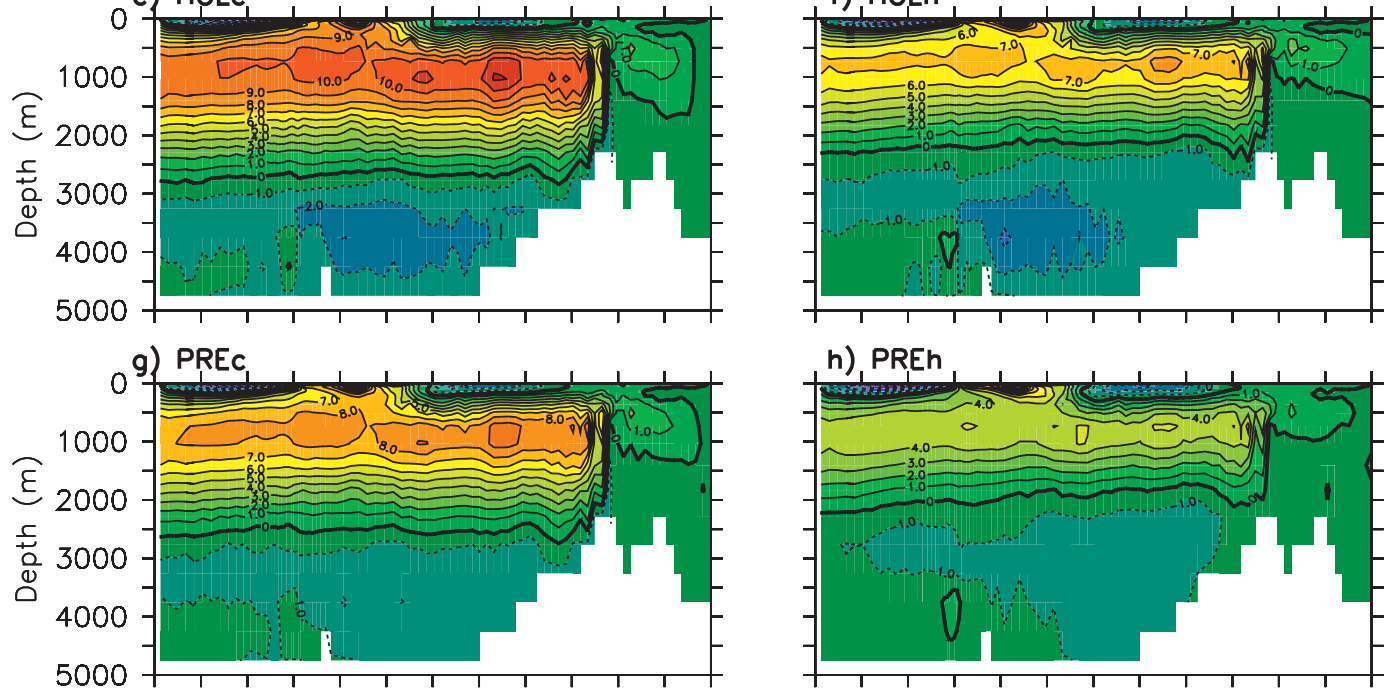

\section{h) PREh}
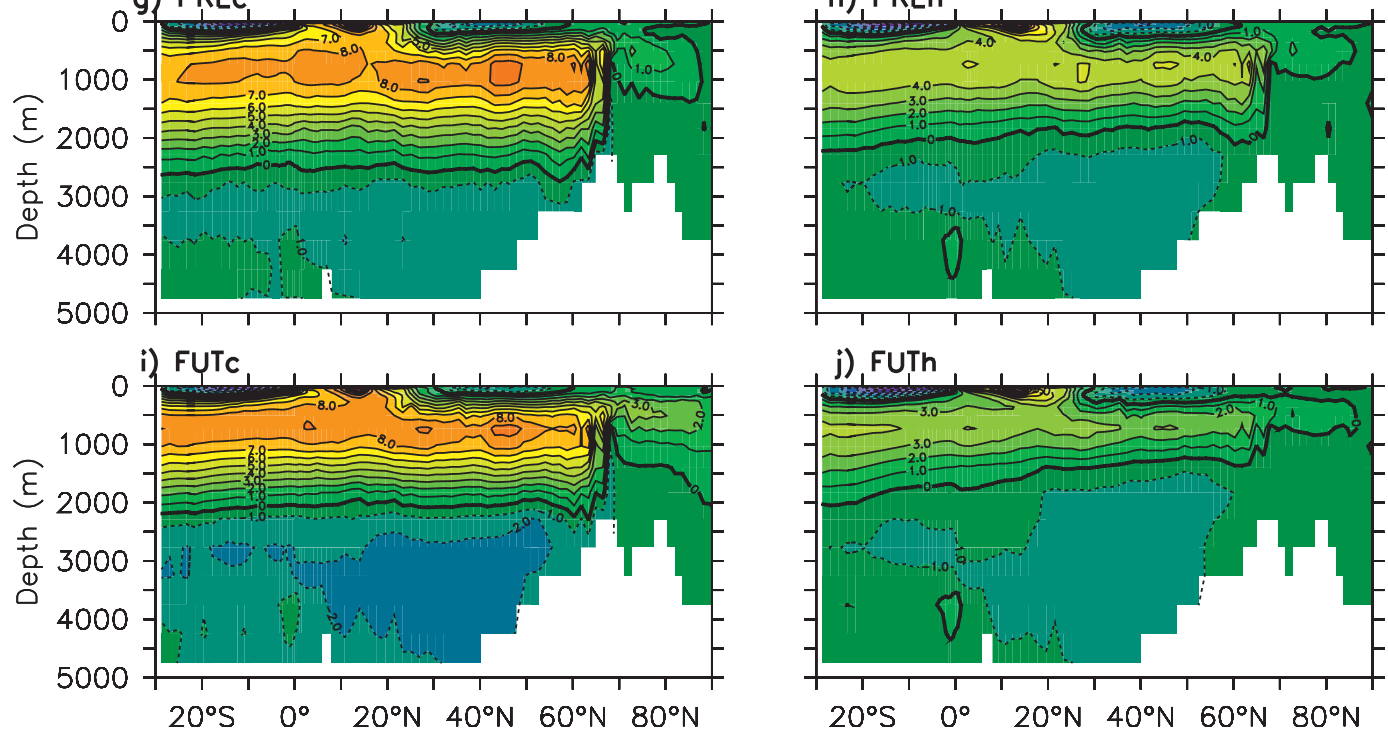

FIG. 2. Meridional overturning streamfunction in the Atlantic averaged annually over the last $30 \mathrm{yr}$ of each experiment: (a) LIGc, (b) LIGh, (c) LGMc, (d) LGMh, (e) HOLc, (f) HOLh, (g) PREc, (h) PREh, (i) FUTc, and (j) FUTh. The contour interval is $1 \mathrm{~Sv}$. Note that the maximum of the AMOC found in this sections are different from the one of Table 3. This is due to the fact that the time mean of the AMOC maximum is different than the maximum of the time mean AMOC. 

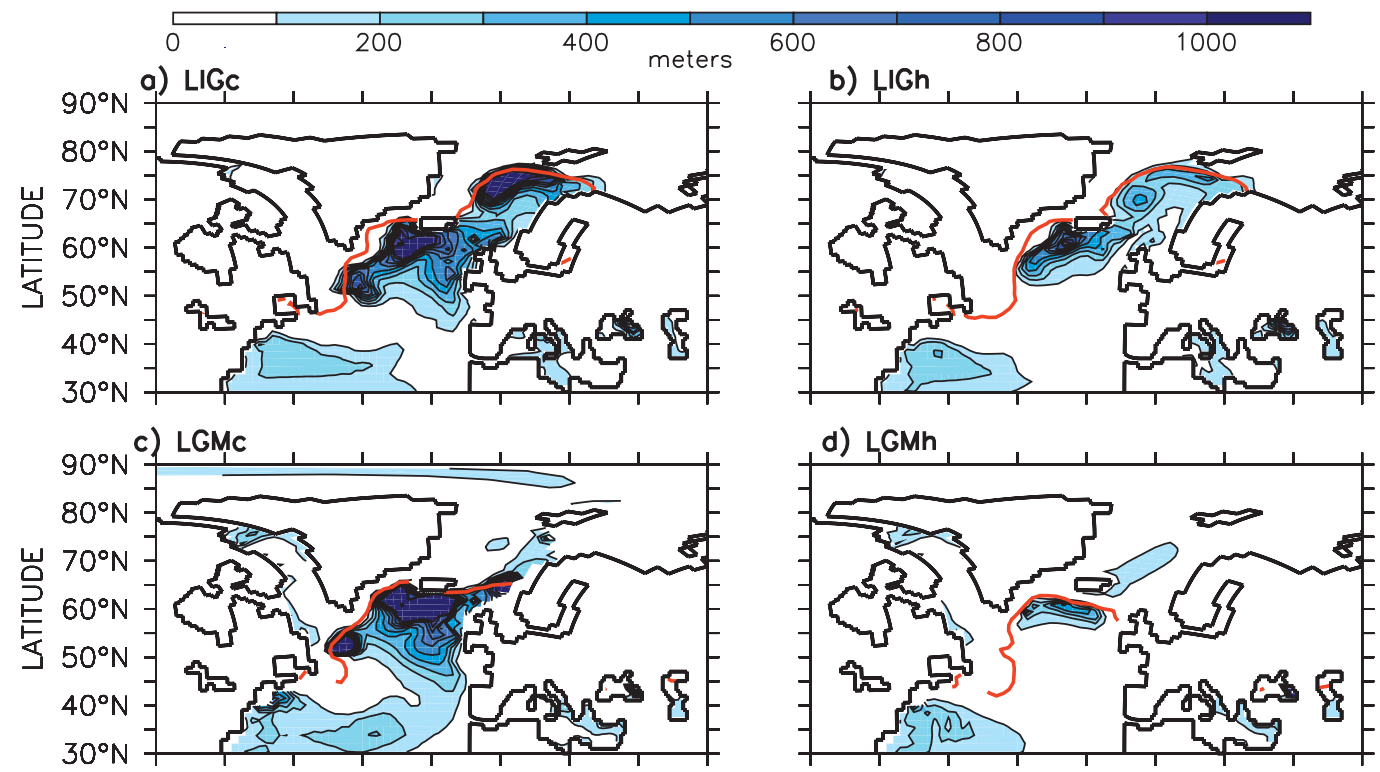

d) LGMh
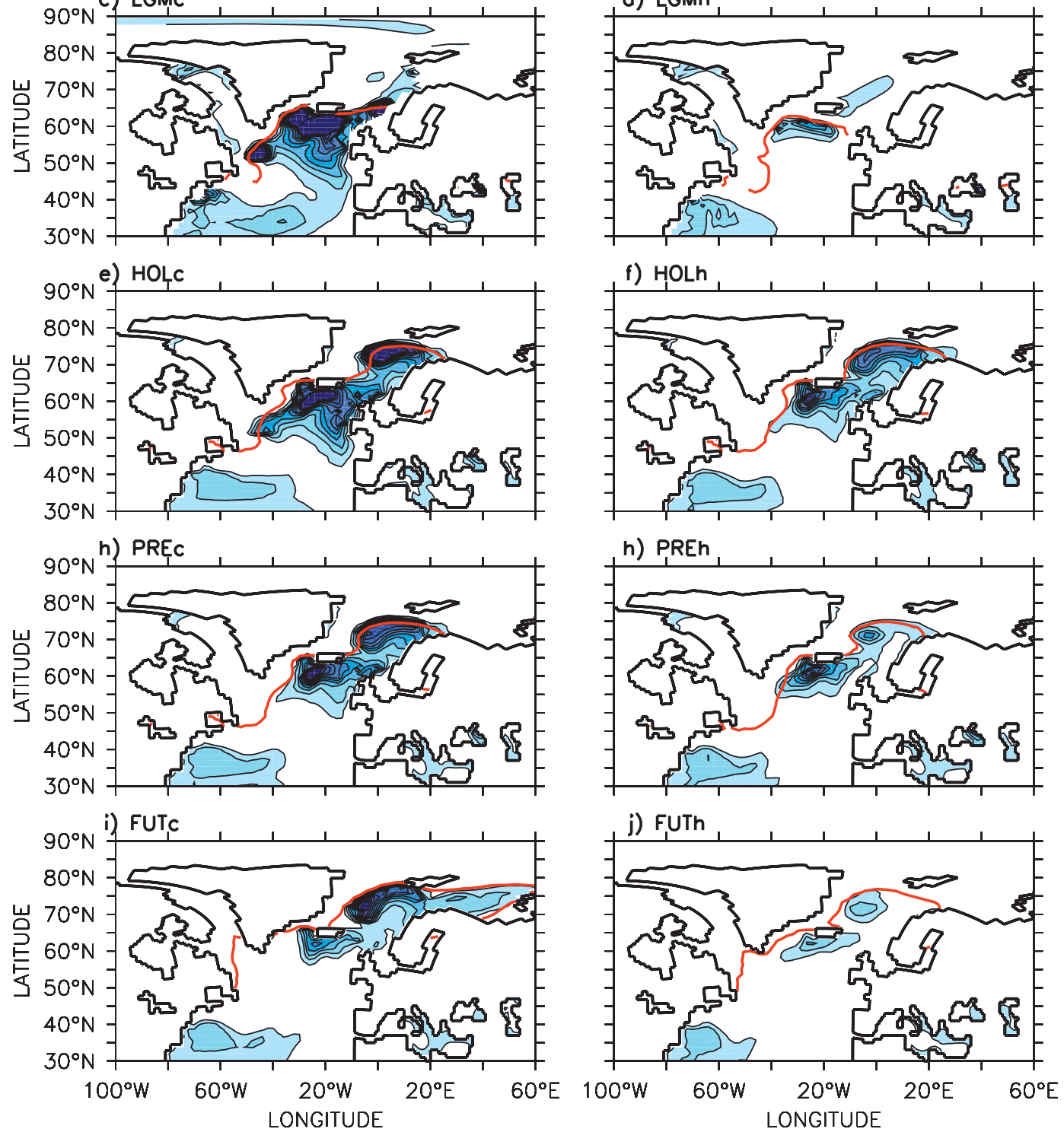

FIG. 3. Mixed layer depth averaged over January-March in the Atlantic for the last $30 \mathrm{yr}$ of each experiment: (a) LIGc, (b) LIGh, (c) LGMc, (d) LGMh, (e) HOLc, (f) HOLh, (g) PREc, (h) PREh, (i) FUTc, and (j) FUTh. The contour interval is $200 \mathrm{~m}$. The limit of the annual mean sea ice cover averaged for the last $30 \mathrm{yr}$ is superimposed in red. 


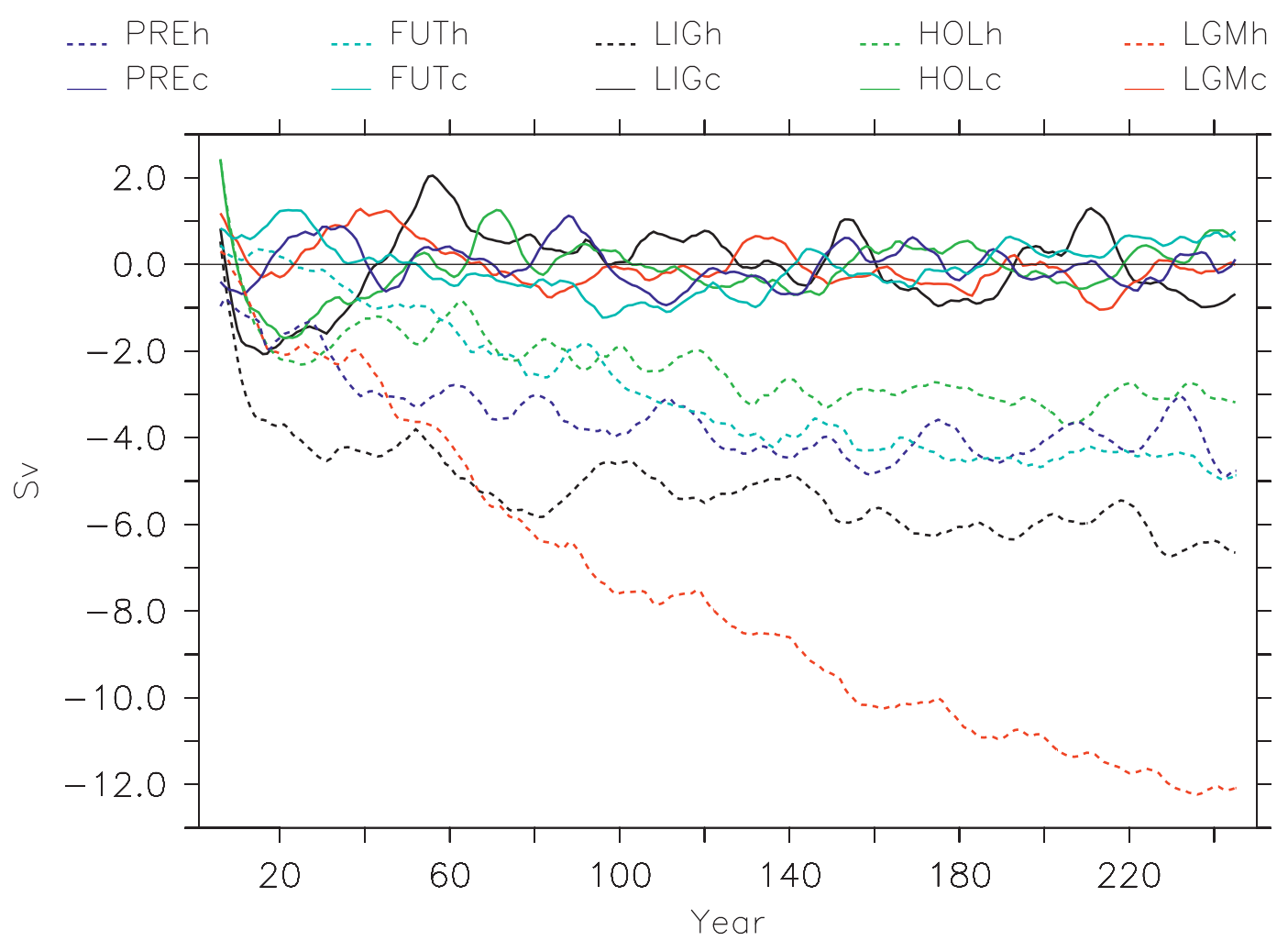

FIG. 4. Time series of the annual mean value of the maximum of the meridional overturning circulation in the Atlantic from $500 \mathrm{~m}$ down to the bottom. The control simulations (solid lines) and the hosing simulations (dashed lines) are shown. For each experiment, the anomalies from the mean value of the control experiments over the $250 \mathrm{yr}$ (see Table 3) are shown; LIG (black), LGM (red), HOL (green), PRE (blue), and FUT (cyan).

\section{a. Large-scale cooling in the Northern Hemisphere}

To explain the mean surface cooling in the Northern Hemisphere, we first study the meridional oceanic heat transport at $25^{\circ} \mathrm{N}$. The reduction of this transport is linear (significant at the $90 \%$ level), with the AMOC weakening across the different experiments (Fig. 7.b). This is in agreement with Boning et al. (1996), who relate the Atlantic heat transport with the AMOC maximum, and with Schneider et al. (2007, their Fig. 7). On the contrary, the mean cooling north of $25^{\circ} \mathrm{N}$ is not proportional to the AMOC weakening (Fig. 7d). For a given oceanic box, SST changes and ocean heat transport changes are indeed not linearly related. Moreover, the oceanic heat transport decrease is partially compensated by an increase in the atmospheric heat transport (Fig. 7c), showing that the models partially simulate the so-called Bjerknes compensation (Bjerknes 1964; Shaffrey and Sutton 2006). This results from a local adjustment in the atmospheric and oceanic column that is not accounted for in the Bjerknes (1964) view.

To quantify the compensation effect in heat transport between ocean and atmosphere, Fig. 8 gives a schematic of the heat budget differences north of $25^{\circ} \mathrm{N}$ between the hosing and control experiments for each climatic state. The Bjerknes compensation, defined here as the ratio between changes in global atmospheric and oceanic heat transport at $25^{\circ} \mathrm{N}$, is less than $40 \%$ in LIG, while it is more than $70 \%$ in FUTh. However, the surface cooling is the largest in the FUTh simulation, while it is rather modest in LIGh (Fig. 7.d). This confirms that the surface cooling north of $25^{\circ} \mathrm{N}$ is not only related to changes in heat transport, but also depends on changes in the radiative forcing, which is assumed to be constant in the Bjerknes compensation scheme.

Figure 8 further shows that the mean shortwave and longwave radiative budgets at the top of the atmosphere north of $25^{\circ} \mathrm{N}$ undergo huge adjustments, which are larger than the sum of the oceanic and atmospheric heat transport changes at $25^{\circ} \mathrm{N}$ for all pairs of simulations. The changes in shortwave radiation appear to be mainly related to changes in sea ice and snow cover (which impact surface albedo) and not cloud cover, since we find a linear relationship (significant at the $80 \%$ level) between temperature changes north of $25^{\circ} \mathrm{N}$ and changes in clear-sky shortwave radiation $\left(\mathrm{SW}_{0}\right.$, Fig. $\left.7 \mathrm{e}\right)$. 


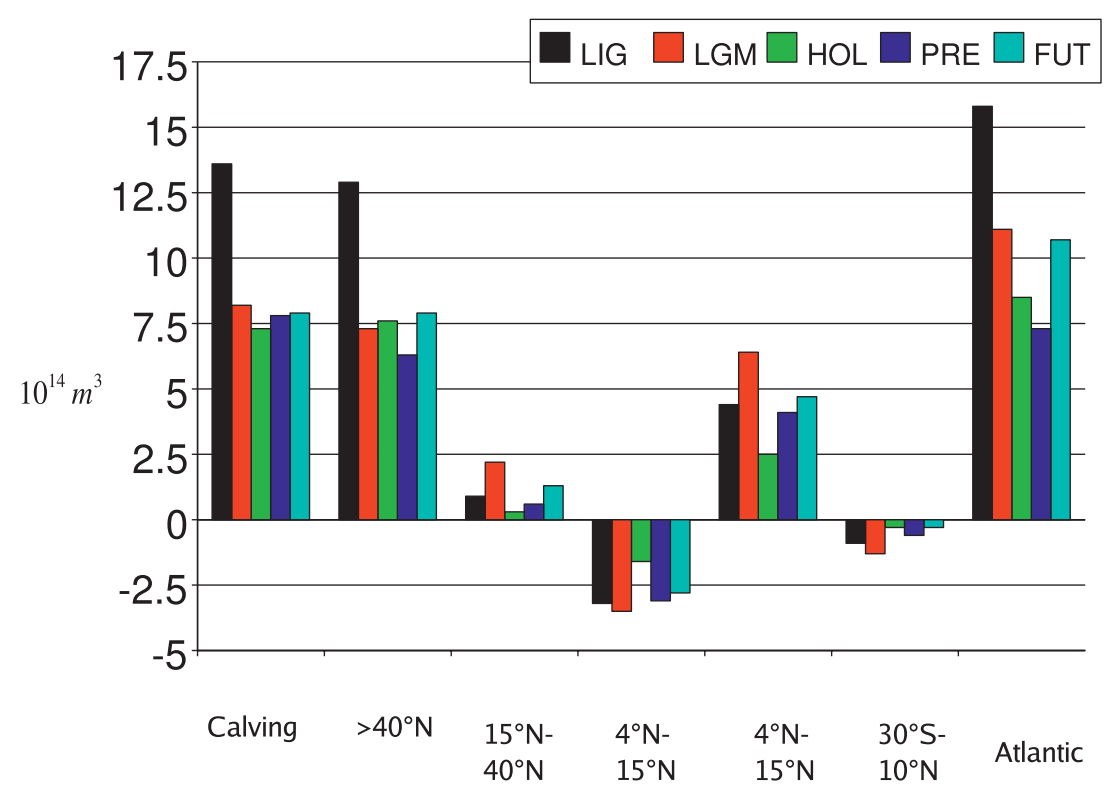

FIG. 5. Differences between hosing and control simulations for the cumulative surface freshwater in the Atlantic (in $10^{14} \mathrm{~m}^{3}$ ), computed over $250 \mathrm{yr}$, in terms of freshwater perturbation (column calving) and net freshwater budget in different latitude bands in the Atlantic (the other columns). LIGh - LIGc (black), LGMh - LGMc (red), HOLh HOLc (green), PREh - PREc (blue), and FUTh - FUTc (cyan). The freshwater is released in the Atlantic, north of $40^{\circ} \mathrm{N}$ in all the experiments, except PREh, where it is put between $50^{\circ}$ and $70^{\circ} \mathrm{N}$ as in Stouffer et al. (2006).

The changes in longwave radiation tend to equilibrate the heat budgets, through the cooling of the surface temperature. Also, the heat storage in the climate components, mostly in the ocean, sea ice, and snow, is not negligible. These changes in sea ice and snow storage represent a transfer of energy from the changes in meridional heat transport toward water phase changes at the surface. This modification then feeds back on the cooling through its impact on the albedo and thus on the radiative forcing. This energy transfer is very efficient for LGMh and PREh, where the ratio of latent energy changes linked to sea ice and snow divided by the energy changes linked to meridional heat transport is equal to 0.68 in both experiments. It is slightly weaker in FUTh (0.58). For LIGh this ratio is very small and is even negative for HOLh, which exhibits a reduction of the sea ice cover resulting from a warmer Arctic Ocean. This shows that the use of a complex model is necessary to capture all of these complex energetic adjustments.

We therefore argue that the sea ice cover increase, which modifies the radiative budget in the high latitudes through the associated albedo increase, is a key player for explaining the cooling north of $25^{\circ} \mathrm{N}$ (Fig. 7e). This effect clearly appears in the Barents Sea in FUTh, where the strongest cooling signal (Fig. 6) coincides with the largest sea ice anomaly (Figs. 3i,j). These changes in sea ice cover are related to differences in the convection in the NA (Fig. 3), and the associated large changes in the vertical heat exchange [process (ii) of the introduction].

We conclude that the cooling in response to freshwater input in the NA is due to changes in oceanic heat transport, but also to complex changes in the radiative budget, notably related with the sea ice cover modifications in response to oceanic changes. As discussed in the next section, sea ice cover is also sensitive to changes in atmospheric forcing, which notably explains the warming pattern east of Greenland noticed in Fig. 6.

\section{b. Mechanisms explaining the warming east of Greenland}

The warming pattern on the eastern coast of Greenland is more pronounced in LIGh and HOLh, for which the Northern Hemisphere cooling is the weakest. It is also present in FUTh and PREh with a lesser magnitude (Fig. 6). Such a regional warming in response to freshwater input has also been found in 5 out of 13 models analyzed by Stouffer et al. (2006), but it was located around the Barents Sea. These authors attribute it to a shift of the convection sites that move outside of the freshwater input region $\left(50^{\circ}-70^{\circ} \mathrm{N}\right)$. This northward shift then prevents sea ice formation because of the large vertical mixing associated with oceanic convection, 
a) LIG

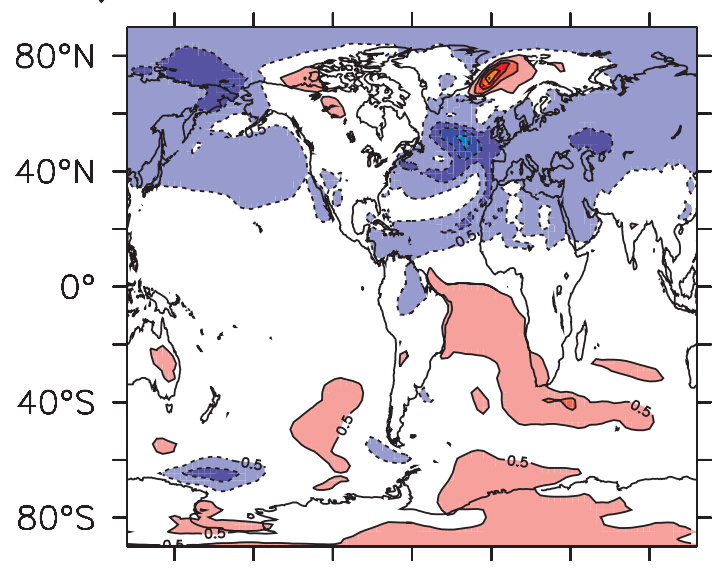

c) $\mathrm{HOL}$

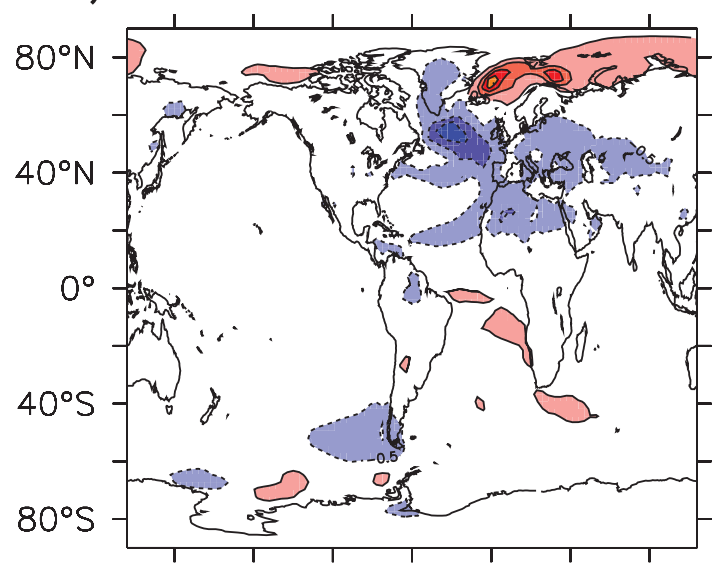

e) FUT

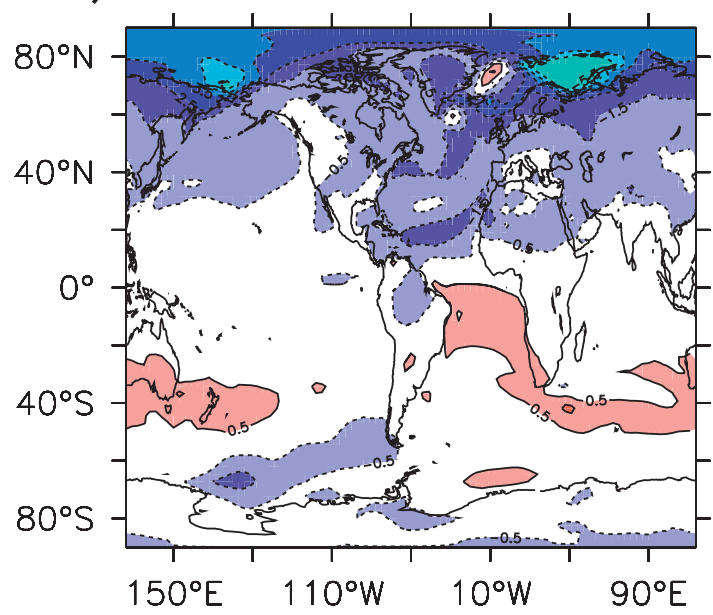

b) LGM

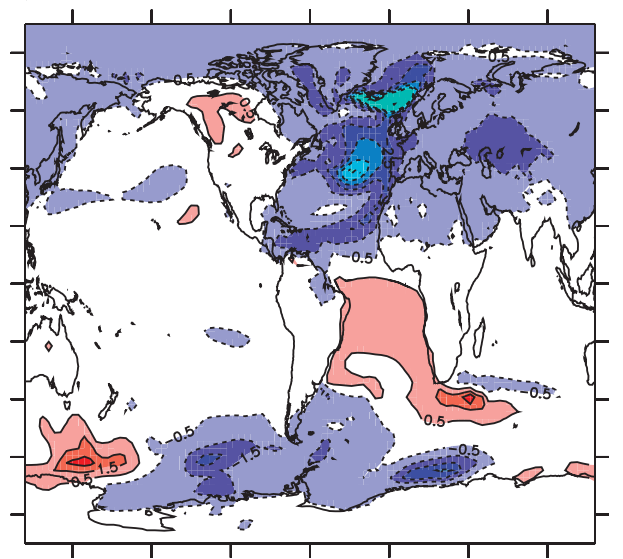

d) PRE
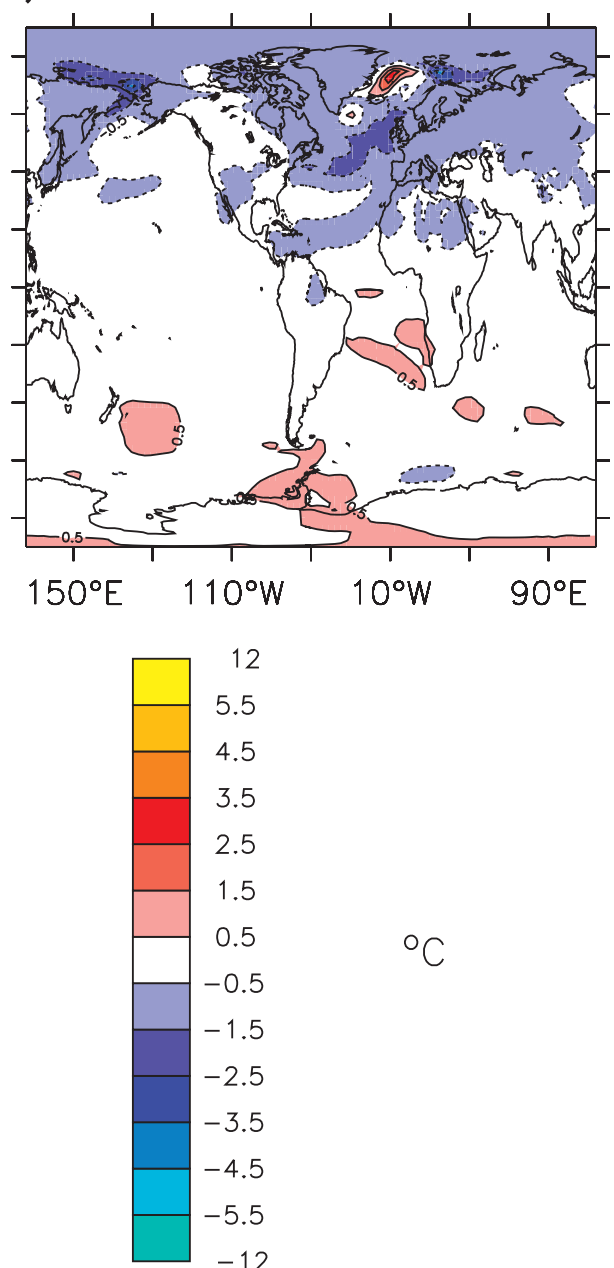

FIG. 6. Surface air temperature averaged annually over the last $30 \mathrm{yr}$ of each experiment: (a) LIGh - LIGc, (b) LGMh - LGMc, (c) HOLh - HOLc, (d) PREh - PREc, (e) FUTh - FUTc. The contour interval is $1^{\circ} \mathrm{C}$, except for the minimum and maximum values. 

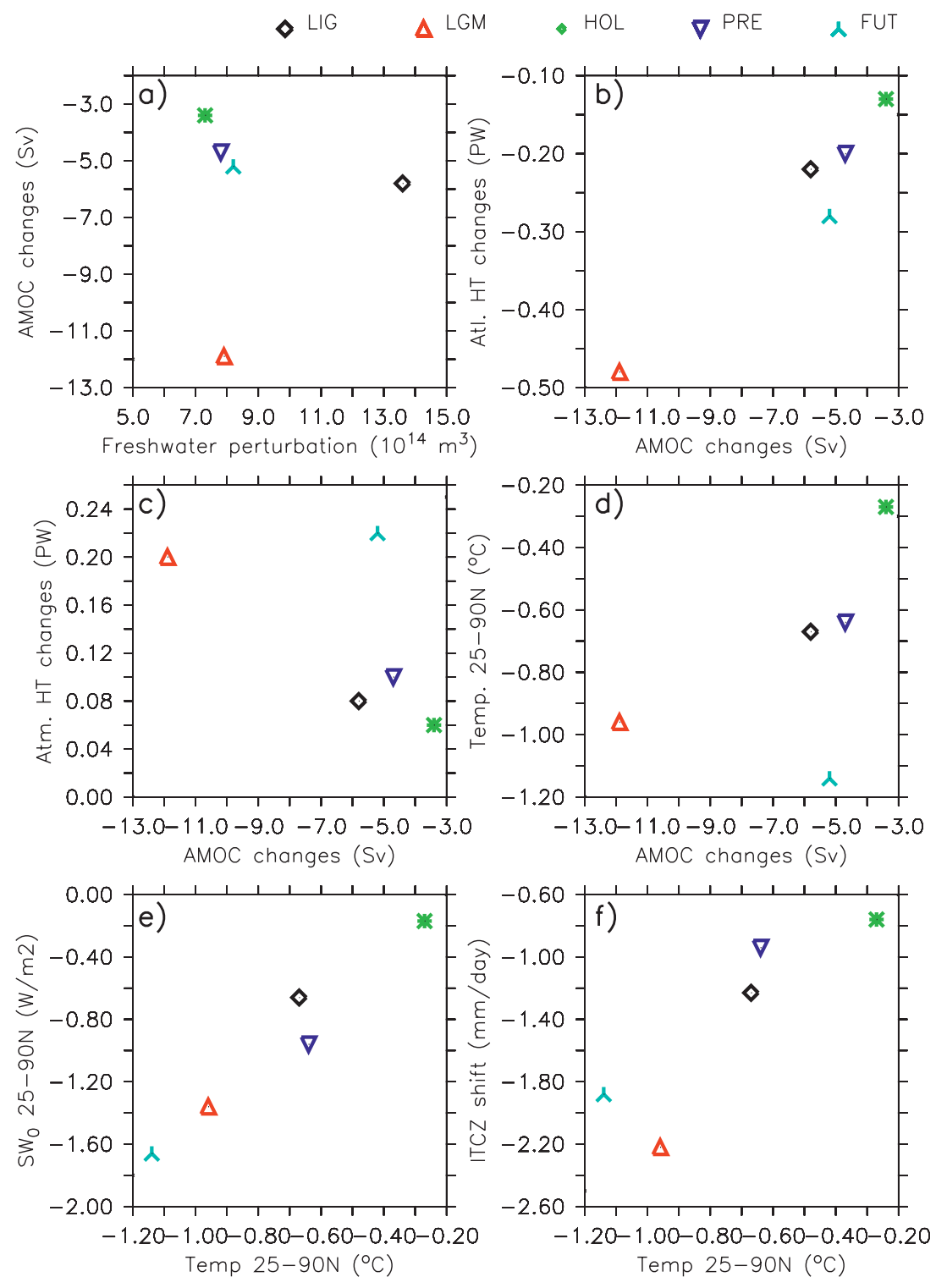

FIG. 7. (a) AMOC changes (Sv) vs freshwater perturbation $\left(10^{14} \mathrm{~m}^{3}\right)$. (b) Oceanic heat transport changes in the Atlantic at $25^{\circ} \mathrm{N}(\mathrm{PW})$ vs AMOC changes (Sv). (c) Atmospheric heat transport changes at $25^{\circ} \mathrm{N}$ vs AMOC changes (Sv). (d) Mean changes in temperature north of $25^{\circ} \mathrm{N}\left({ }^{\circ} \mathrm{C}\right)$ vs AMOC changes (Sv). (e) Mean changes in net outgoing shortwave radiation at the top of the atmosphere without the effect of cloud (clear-sky calculation) north of $25^{\circ} \mathrm{N}$. (f) ITCZ shift (defined as the maximum minus the minimum changes in precipitation in Fig. 11) vs mean temperature change north of $25^{\circ} \mathrm{N}\left({ }^{\circ} \mathrm{C}\right)$. All of the results are computed using a time average over the period of 220-250 of each experiment. Note that the axes are not the same in the different panels.

which increases the mixed layer heat capacity. In the present study, all of the simulations that exhibit a warming east of Greenland also show a negative anomalous sea ice cover in this region (Fig. 9). However, the latter is not related to a significant change in mixed layer depth (Fig. 3), but rather to a wind stress anomaly. Indeed, Fig. 9 shows southwesterly anomalous winds be- tween Greenland and Iceland in all simulations, including LGMh. This anomalous wind brings warmer air masses along the eastern coast of Greenland and contributes to the melting of sea ice there. The sea ice drift, which normally goes from the Fram Strait toward the south tip of Greenland in all of the control experiments, is also reduced in the hosing experiments (not shown). This 

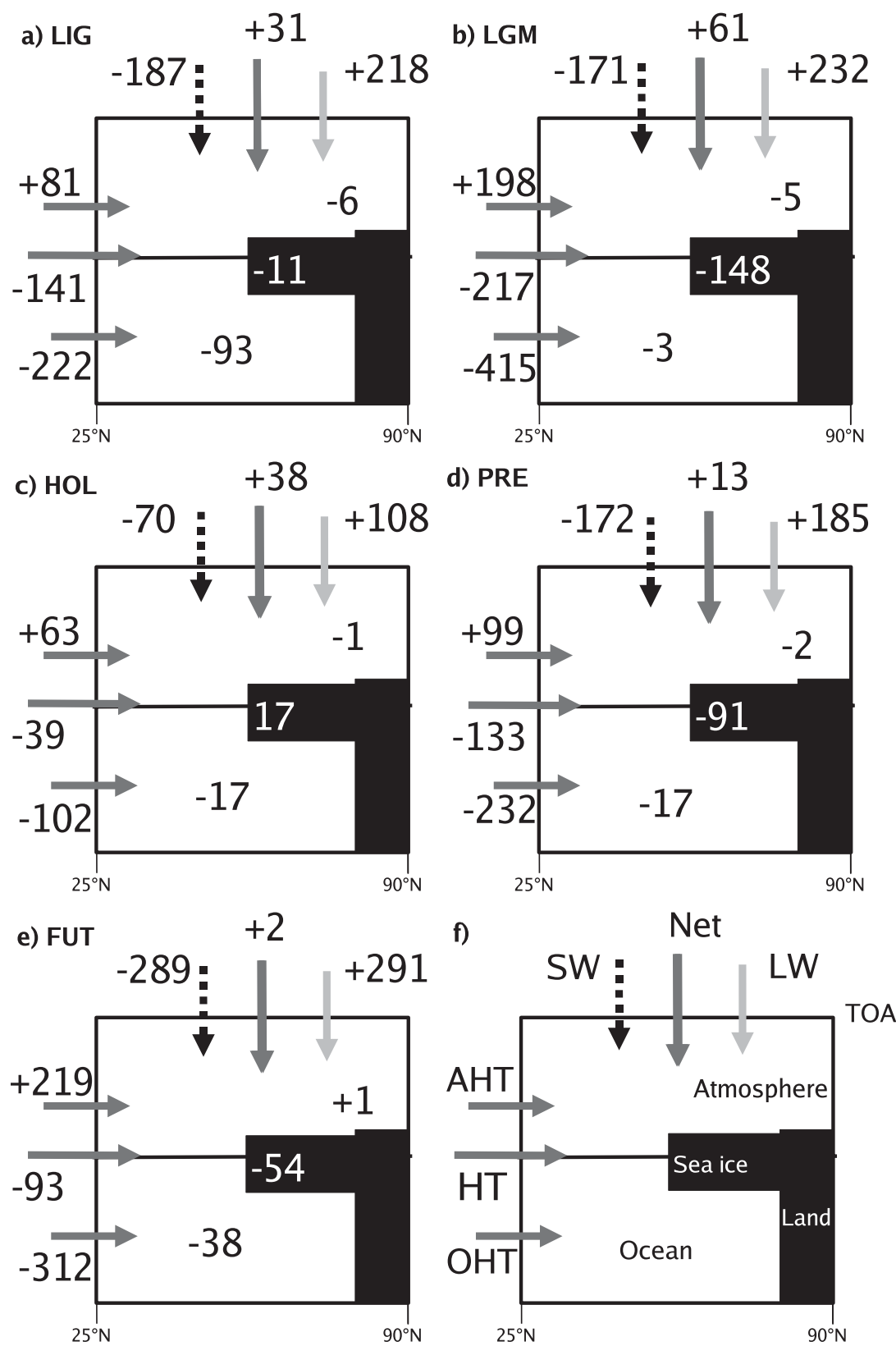

FIG. 8. Energy budget differences (TW) between hosing and control experiments averaged over years 220-250. The explanation of the different components of this budget appears in (f). Oceanic and atmospheric heat transport (OHT and AHT, respectively), taken at $25^{\circ} \mathrm{N}$ and total AHT + OHT (HT). At the top of the atmosphere (TOA), the net radiative flux is represented (plain arrow). Shortwave (SW) flux (dotted arrow) and longwave (LW) flux (gray arrow) are shown. The figures given in the atmosphere, sea ice + snow + land + ocean box stand for the changes in energy storage of each component, respectively. Note that the storage in land is negligible. (a) LIGh - LIGc, (b) LGMh - LGMc, (c) HOLh HOLc, (d) PREh - PREc, and (e) FUTh - FUTc.

may be due to either the direct effect of the changes in wind stress (pushing the sea ice out of the region) or the presence of warmer air masses in this region (melting the sea ice). In addition, the oceanic heat transport by the wind-driven gyre increases by a few tenths of petaWatt (PW, depending on the experiment, not shown) across a section going from the tip of Greenland up to Norway. This third effect also favors the melting of sea ice on the 


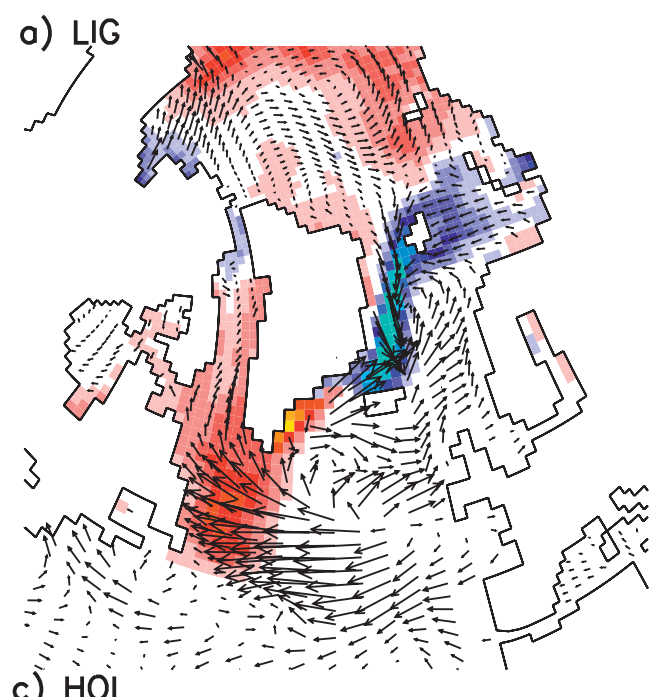

c) $\mathrm{HOL}$
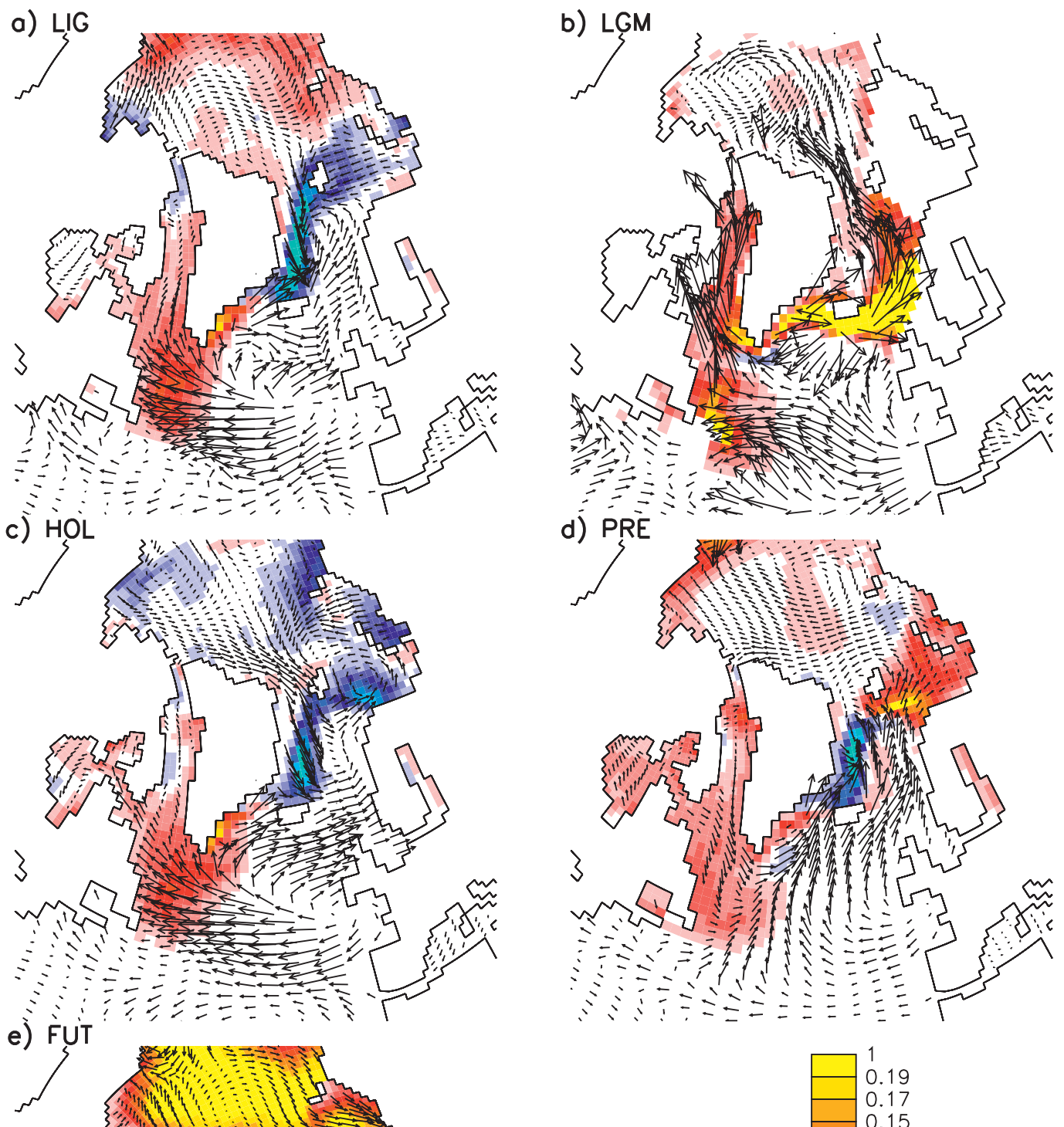

e) FuT
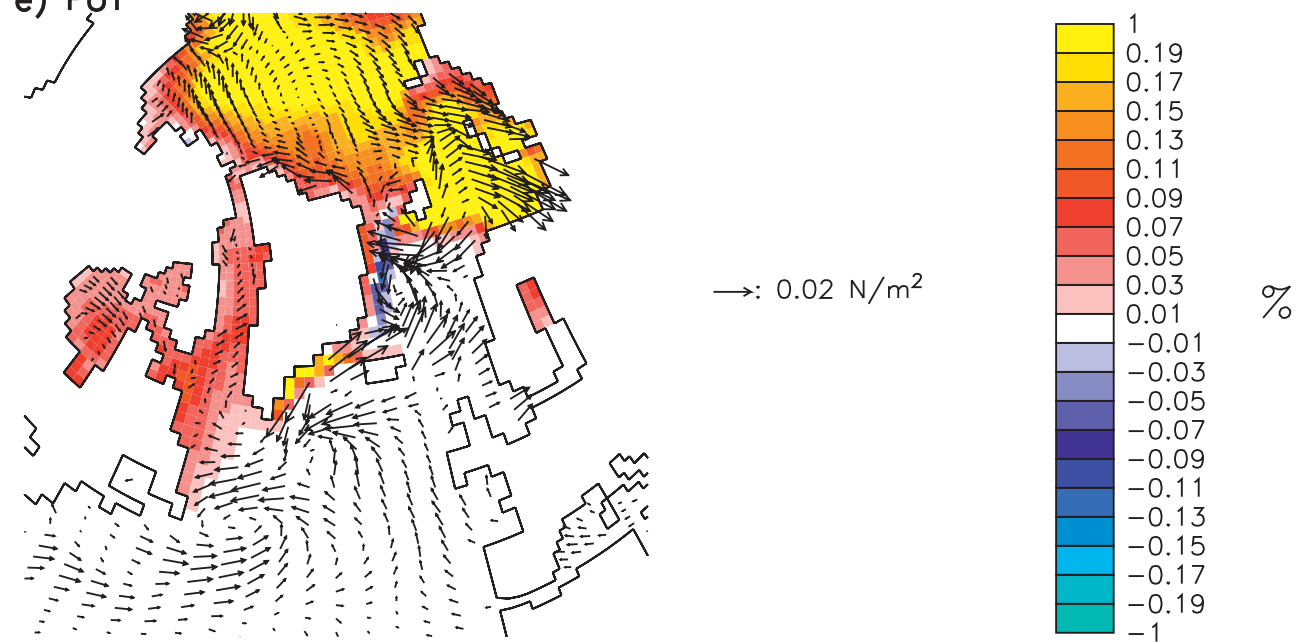

FIG. 9. Sea ice cover defined as the ratio occupied by sea ice in each cell over the whole cell area and wind stress $\left(\mathrm{N} \mathrm{m}^{-2}\right.$ ) differences averaged annually over the $30 \mathrm{yr}$ of each experiment. (a) LIGh - LIGc, (b) LGMh - LGMc, (c) HOLh - HOLc, (d) PREh - PREc, and (e) FUTh - FUTc. 
eastern coast of Greenland and contributes to the warming of the entire Arctic Ocean. The fact that no such pattern is found in LGMh can be explained by the mean climate state, with a larger sea ice thickness in this region that prevents the wind changes to have a sufficient impact to melt the sea ice.

The regional anomalous southwesterly wind is related to an anomalous positive sea level pressure over Greenland. The latter is seen in all hosing simulations, including LGMh (Fig. 10). Another general characteristic of the atmospheric response is a negative anomaly in the extratropical North Pacific close to the Aleutian low. This large-scale pattern resembles the Aleutian low-Icelandic Low (AL-IL) seesaw, described in present-day reanalyses by Honda et al. (2001), that has a clear signature on the interannual variability of the Northern Hemisphere. The dynamics of this pattern is thought to be internal to the wintertime circulation and is related to storm-track dynamics (Honda et al. 2005).

We therefore propose that the warming pattern along the eastern coast of Greenland is due to the adjustment of the atmosphere dynamics in response to the initial large-scale cooling. The large-scale change in the atmospheric circulation modifies the wind pattern regionally, reduces the sea ice cover around the east coast of Greenland, and leads to a warming there. In FUTh and PREh, this signal is partly hidden by the strong large-scale cooling. The reason for the adjustment of the atmospheric circulation remains unclear however, and will necessitate a dedicated study to be clarified.

Such a local warming in response to a freshwater input in the NA has also been simulated by Saenko et al. (2007). They found a similar mechanism implying wind stress pattern changes, but in their simulations the warming was due to a local (around the Labrador Sea) rather than to a large-scale (north of $40^{\circ} \mathrm{N}$ in the NA) freshwater input. Here we find that even for a uniform large-scale freshwater input, a regional warming can be simulated in the NA (as long as the freshwater forcing is relatively weak).

Finally, we have noticed that the warming pattern east of Greenland is larger in LIGh and HOLh than in the other climates (Fig. 9). We explain this by the insolation forcing differences among the experiments. The shortwave radiation forcing during the summer season is larger at $65^{\circ} \mathrm{N}$ in LIG and HOL as compared to the other climates. The storage of energy from shortwave radiation at $65^{\circ} \mathrm{N}$ is therefore amplified in the LIG and HOL doublets when sea ice is not capping the ocean. There is indeed up to $20 \mathrm{~W} \mathrm{~m}^{-2}$ more shortwave radiation captured by the ocean in May in LIGh as compared to PREh in a box located along the Greenland coast $\left(65^{\circ}\right.$ $80^{\circ} \mathrm{N}, 30^{\circ}-10^{\circ} \mathrm{W}$ ), and up to $10 \mathrm{~W} \mathrm{~m}^{-2}$ in HOLh as compared to PREh. This additional captured energy helps to keep this region ice free and amplifies the effect of anomalous southwesterly winds on the sea ice cover, as described before. The intensity of the seasonal forcing in HOLh and LIGh therefore increases the efficiency of the regional adjustment described above and leads to a larger warming in these simulations, as well as a larger strengthening of the heat transport from the NA into the Nordic seas.

\section{Changes in precipitation patterns and freshwater budget}

\section{a. Southward shift of the Atlantic ITCZ}

As seen in the introduction, an important feature related to freshwater input in the NA is its impact on the tropical precipitation pattern. Figure 11 show that for all of the climates considered in this study, the freshwater flux induces a southward shift of the ITCZ in the Atlantic as well as in the eastern Pacific. This is a traditional response to freshwater input found in several state-ofthe-art OAGCMs for preindustrial conditions (Stouffer et al. 2006; Timmermann et al. 2007). Here we show that this response is robust whatever the baseline climatic conditions. However, the intensity of this shift and its longitudinal extension (especially over the western Pacific and Indian Oceans) differ for the different simulations (Fig. 11).

Figure 12 quantifies the intensity of the shift, through the differences in precipitation between the control and the hosing experiments, zonally averaged from $80^{\circ} \mathrm{E}$ to $20^{\circ} \mathrm{W}$ in the tropical Atlantic. North of the equator, the largest decrease in precipitation is found for LGMh and FUTh. These two simulations also have the largest increase in precipitation south of the equator. We can define the intensity of the Atlantic ITCZ shift as the difference between the maximum changes south of the equator minus the minimum north of it. Figure $7 \mathrm{f}$ shows that this intensity of the Atlantic ITCZ shift evolves in the same direction as the temperature changes north of $25^{\circ} \mathrm{N}$, even though the relationship is not strictly linear, because the statistical significance for linearity is only true at the $60 \%$ level.

The changes in precipitation in the tropical region are due to both changes in oceanic heat transport and a meridional atmospheric bridge. The latter propagates the cooling signal from the NA to the tropical Atlantic through a so-called subtropical wind-evaporation-SST feedback. Indeed, the NA cooling induces an anomalous anticyclonic circulation that strengthens the trade winds and the evaporation in the subtropics, thereby enhancing the cooling there and creating an SST dipole with the 

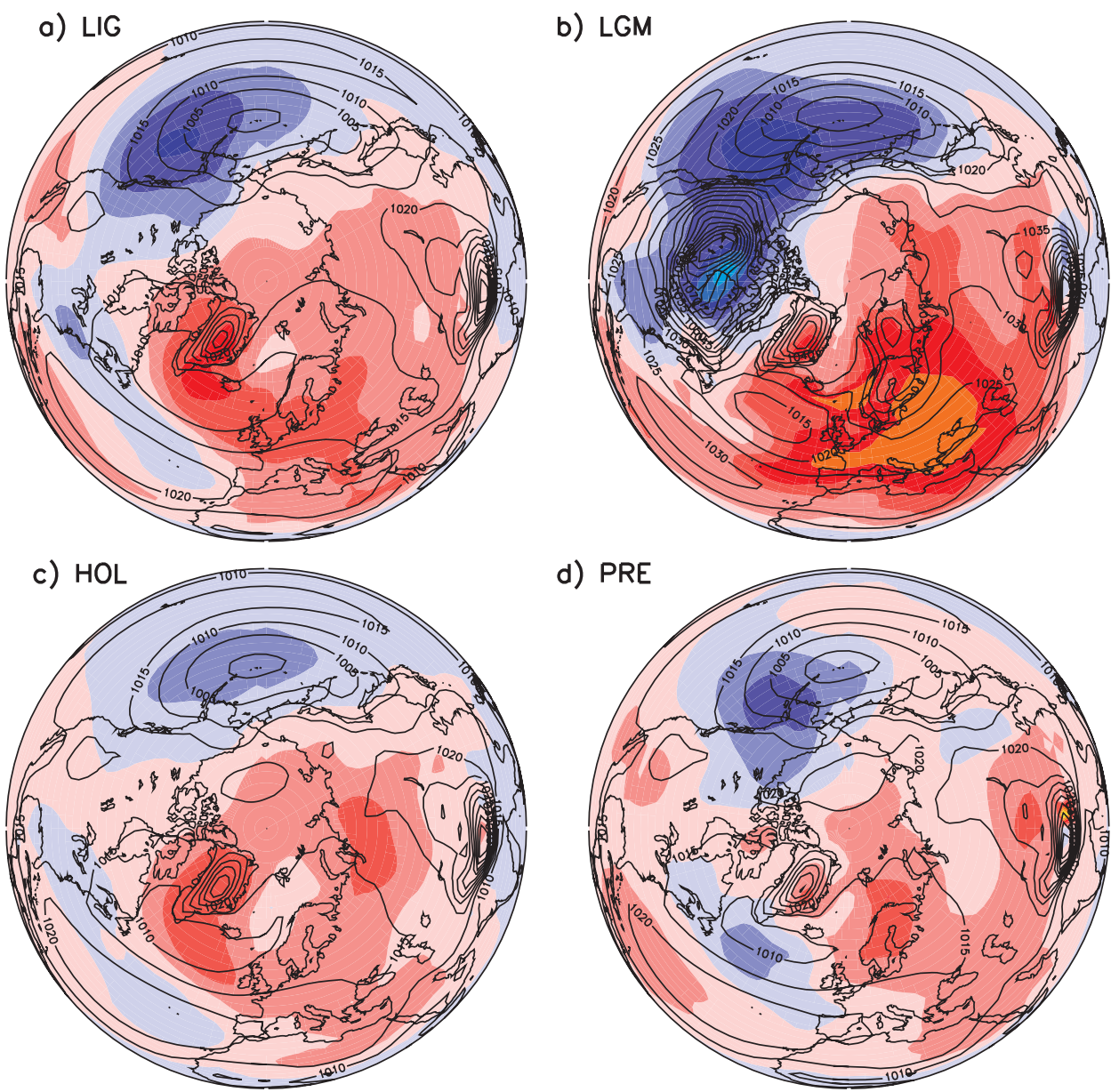

d) PRE
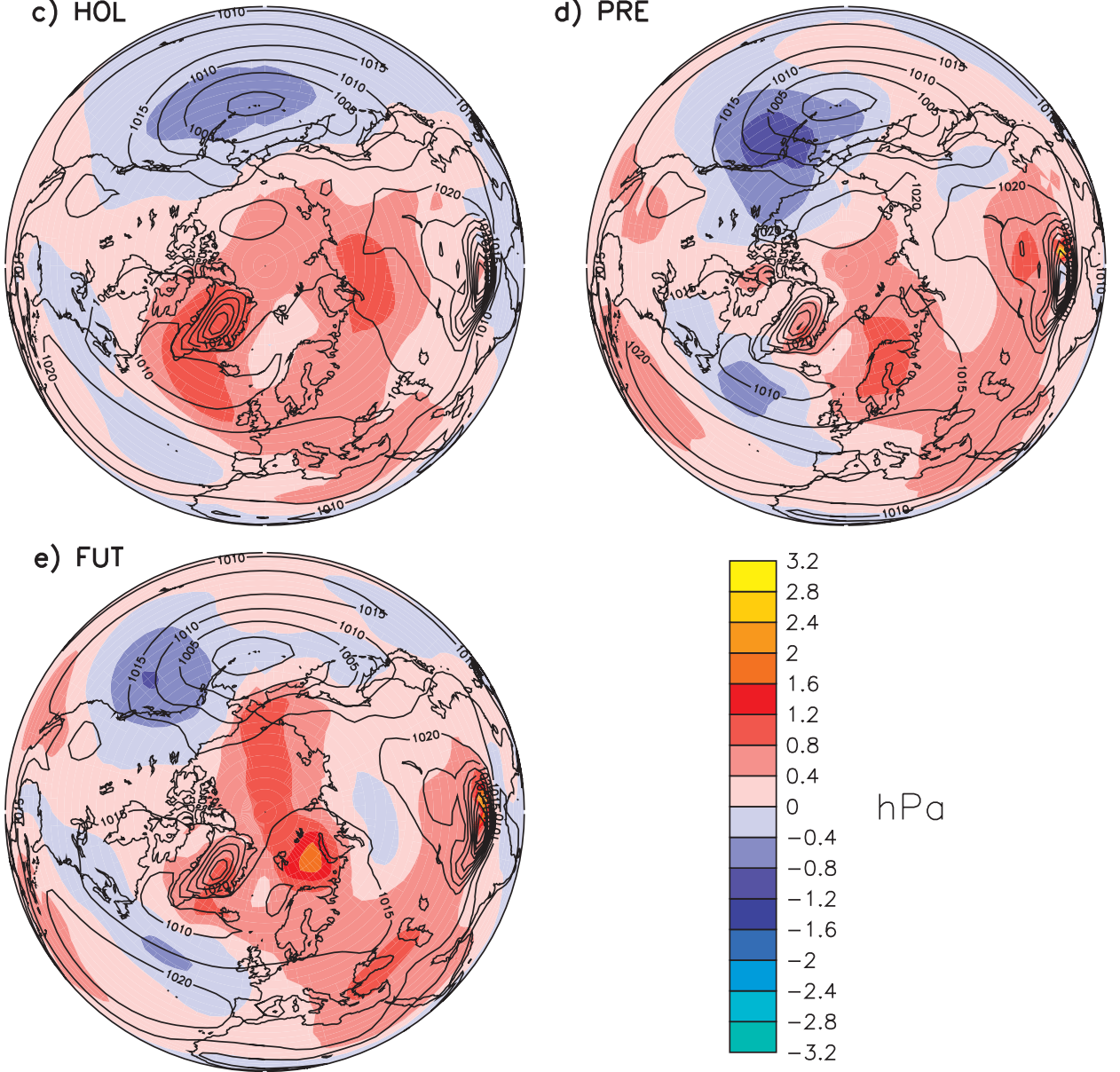

FIG. 10. Sea level pressure (hPa) averaged annually over the last $100 \mathrm{yr}$ of each experiment. This period for the average is larger than for the other figures and has been chosen in order to limit the effect of the large internal variability occurring around the NA. The colored regions correspond to the anomalies between hosing and control experiments. The contours in each figure display the control climate sea level pressure for (a) LIG, (b) LGM, (c) HOL, (d) PRE, and (e) FUT. 
o) LIG

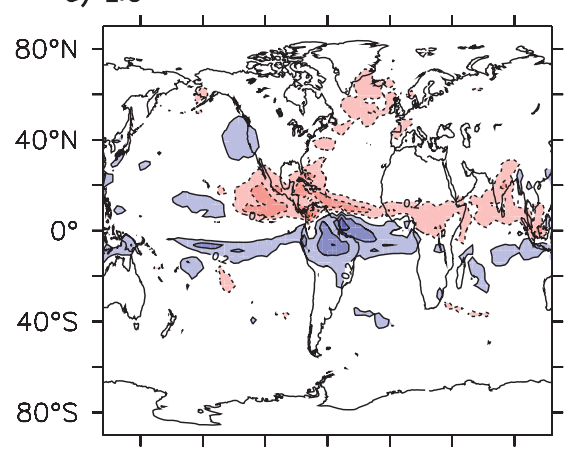

c) $\mathrm{HOL}$

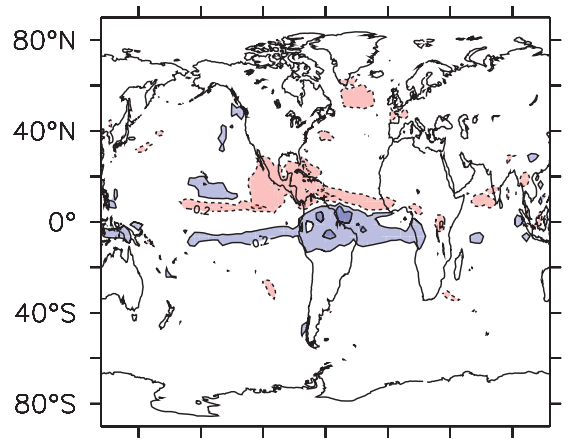

e) FUT

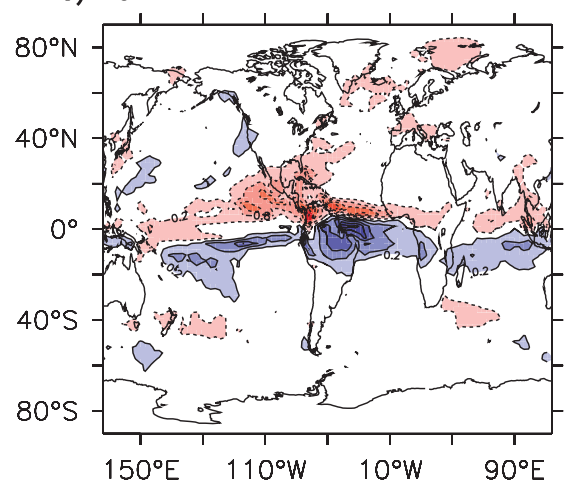

b) LGM

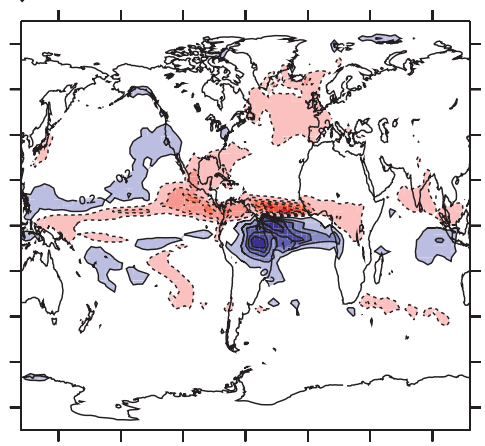

d) PRE
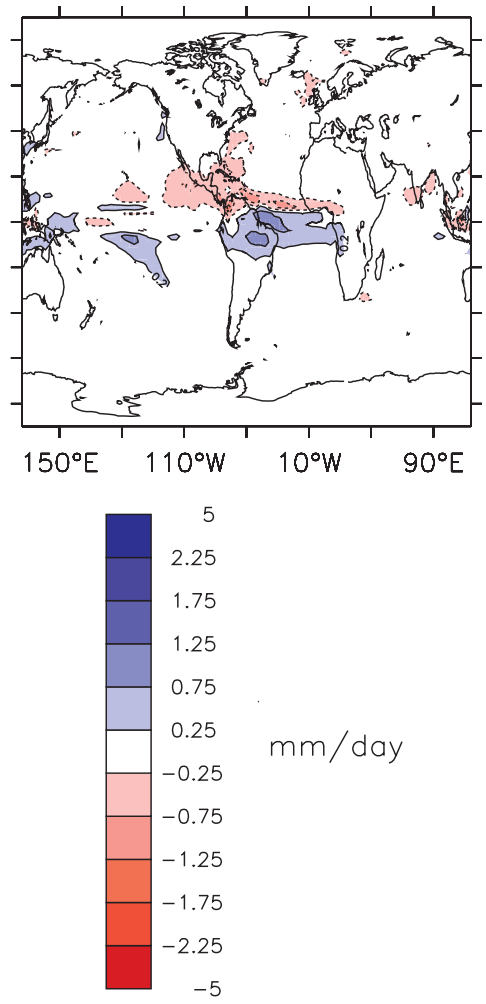

FIG. 11. Precipitation averaged annually over the last $30 \mathrm{yr}$ of each experiment. The contour interval is $0.5 \mathrm{~mm}$ day $^{-1}$. (a) LIGh - LIGc, (b) LGMh - LGMc, (c) HOLh - HOLc, (d) PREh - PREc, and (e) FUTh - FUTc.

region located farther south. This leads the ITCZ to shift southward. This type of mechanism appears to be at work in our simulation according to Fig. 13, shown for the end of the simulation (this propagation is also seen at the beginning of the simulations, not shown). The NA SST anomalies are associated with northeasterly wind stress anomalies north of the equator. Approaching the equator, the zonal component of the wind stress anomalies change their direction and become northwesterly, leading to a characteristic C-shaped pattern of anomalous wind. In association with the oceanic tunnel in re- sponse to the decrease in deep-water formation in the NA (Kawase 1987), this leads to a cross-equatorial SST dipole and a southward ITCZ shift, as proposed by Wu et al. (2007) or Chiang et al. (2008).

\section{b. Southward shift of the Pacific ITCZ}

Several recent analyses of marine sediment cores show an SST and precipitation decrease in the northeastern tropical Pacific warm pool associated with NA high-latitude cooling (e.g., Leduc et al. 2007). A similar feature is present in all of our simulations (Figs. 14 and 15, 


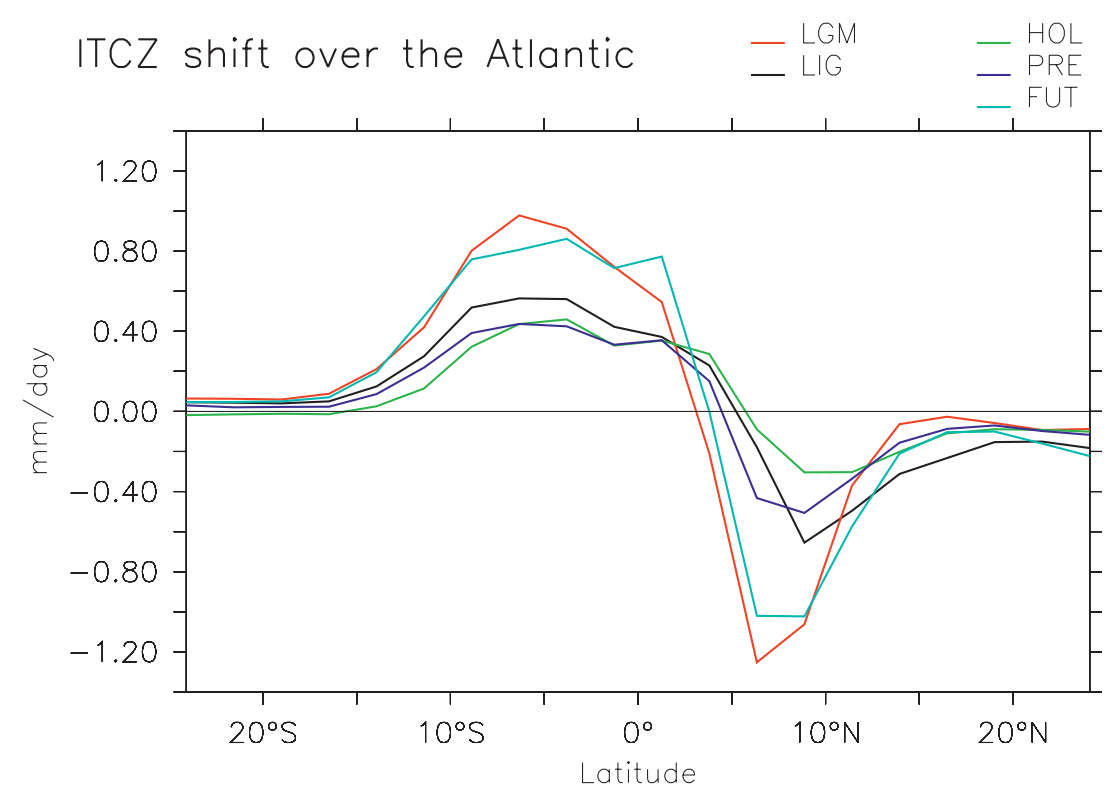

FIG. 12. Mean annual precipitation averaged over the Atlantic $\left(80^{\circ} \mathrm{E}-20^{\circ} \mathrm{W}\right)$ for the last $30 \mathrm{yr}$ of each experiment against latitude. LIGh - LIGc (black), LGMh - LGMc (red), HOLh - HOLc (green), PREh - PREc (blue), and FUTh - FUTc (cyan).

colors). Anomalous cooling is maximum in winter/spring, when the climatological northeast trade winds prevail across the isthmus (Xie et al. 2008), and is associated with anomalous northeasterly winds across Central America and the eastern Pacific. This was shown to be very robust in a water-hosing experiment using state-ofthe-art OAGCMs under modern boundary conditions (Timmermann et al. 2007). Our results suggest that it is also robust under different mean climatic conditions. Xie et al. (2008) also showed that the cooling decreases and even reverses signs in boreal summer/fall because of a reversal of the climatological winds in the northeastern tropical Pacific winds. As in most other OAGCMs, this wind reversal is not reproduced in our model (not shown). The anomalous cooling of the northeastern tropical Pacific still decreases in all simulations in this season. It reverses sign at the equator in most of them.

Reduced precipitation (Fig. 14) associated with the surface cooling in the northeast tropical Pacific (Fig. 15) is consistent with the modeling study of Zhang and Delworth (2005) and observations by Leduc et al. (2007). As in the tropical Atlantic, in all but LGMh, an active ocean-atmosphere coupling maintains the north-south pressure gradient, anomalous northerly winds, and, thus, anomalous warming over the south tropical Pacific. Furthermore, as in the Atlantic, the cooling north of the equator contributes to an overall strengthening of the Hadley cell and a trade wind intensification (Fig. 14), favoring a southward displacement of the ITCZ in the Pacific. Precipitations are indeed slightly enhanced south of the equator in all simulations (Fig. 14). This effect is strongest in January-May, when SST anomalies trigger the atmospheric deep convection. The response is particularly clear above the very warm ocean of FUTh. Interestingly, the anomalous meridional asymmetry in SST is strongest and most persistent in LIGh, where enhanced insolation in summer largely favors a symmetrical mean state in the tropical Pacific. This is in line with results of Okajima et al. (2003) who showed that a symmetrical climatology favors the development of the meridional dipole mode. In PREh, HOLh, and FUTh, the mean meridional SST gradient is maximum in the baseline simulations in September-October (not shown). In this season, the meridional asymmetry does not establish as clearly as in LIGh. Rather, the anomalous cooling of the north tropical Pacific propagates to about $10^{\circ} \mathrm{S}$, together with a shallowing of the $20^{\circ} \mathrm{C}$ isotherm depth and following active anomalous easterlies (Fig. 15). This is the signature of the classical positive Bjerkness equatorial feedback (Bjerknes 1966, 1969).

It is evident from Figs. 14 and 15 (colors) that the response in LGMh in terms of SST and wind anomalies constitutes an exception to the other climates. However, contours in Fig. 15 shows that the oceanic subsurface response is very close to that of the other climates, with an anomalous deepening of the $20^{\circ} \mathrm{C}$ isotherm in the northern subtropics and anomalous shallowing in the southern subtropics. An explanation for this different surface response could lie in the fact that LGMc is significantly colder than the other climates. This probably 


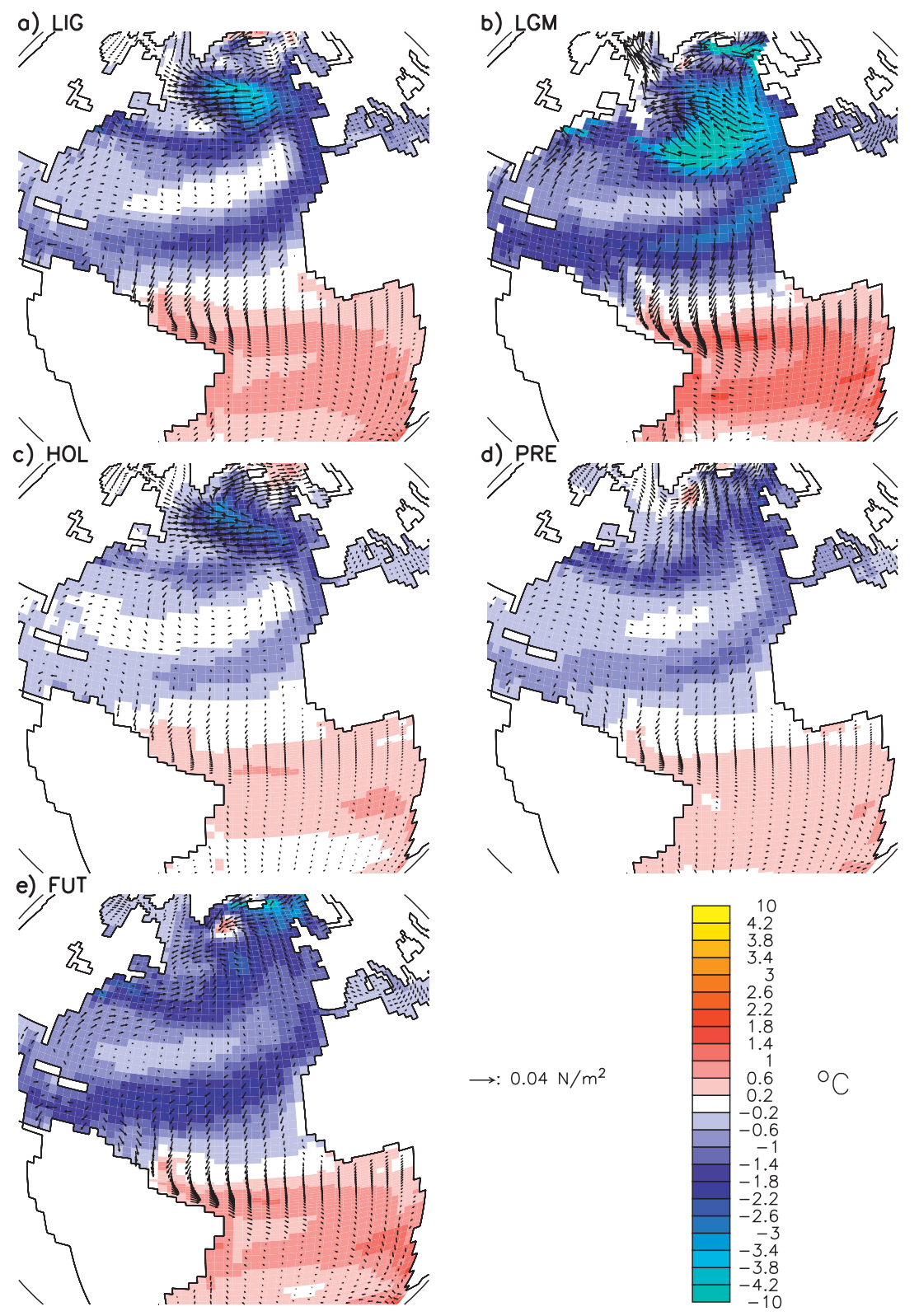

FIG. 13. SST $\left({ }^{\circ} \mathrm{C}\right)$ and wind stress $\left(\mathrm{N} \mathrm{m}^{-2}\right)$ changes for the last $30 \mathrm{yr}$ of each experiment. (a) LIGh - LIGc, (b) LGMh - LGMc, (c) HOLh - HOLc, (d) PREh - PREc, (e) FUTh FUTc.

limits important air-sea tropical couplings and thereby prevents the propagation of the surface northeastern tropical Pacific anomalies to the Southern Hemisphere.

\section{c. Freshwater budget over the Atlantic}

The moisture transport between the Pacific and the Atlantic basins is affected by the tropical atmospheric circulation changes accompanying the ITCZ shift. This has been hypothesized to be a positive feedback for the AMOC by Leduc et al. (2007). In our hosing simulations the freshwater budget (precipitation plus runoff minus evaporation) over the entire Atlantic increases more than the freshwater input through calving north of $40^{\circ} \mathrm{N}$ (Fig. 16), except in PREh. This increase is maximum for LGMh, where an extra $2.8 \times 10^{14} \mathrm{~m}^{3}$ or $39 \%$ of the freshwater perturbation is found, while the extra accumulation remains close to $30 \%$ for the other experiments (except for PREh where the decrease represents $8 \%$ of the perturbation). This is not negligible, but, as noticed by Vellinga et al. (2002) and Krebs and 
(a)

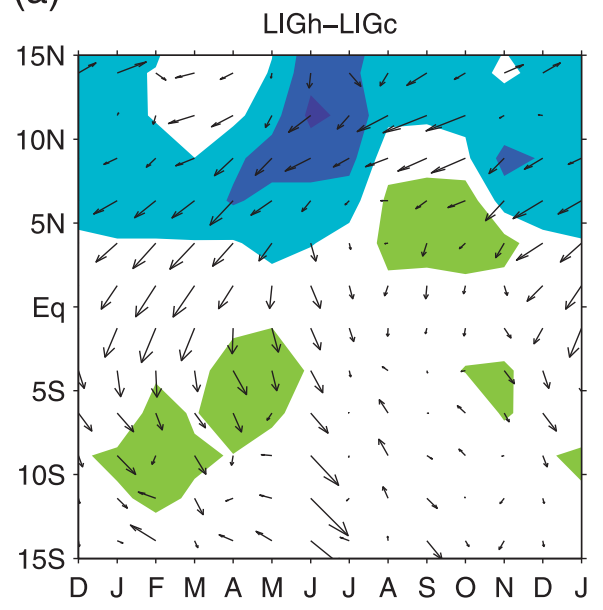

(c)

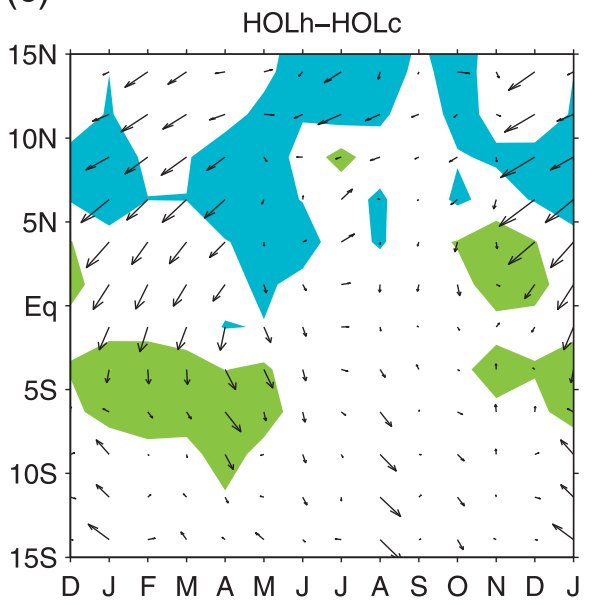

(b)

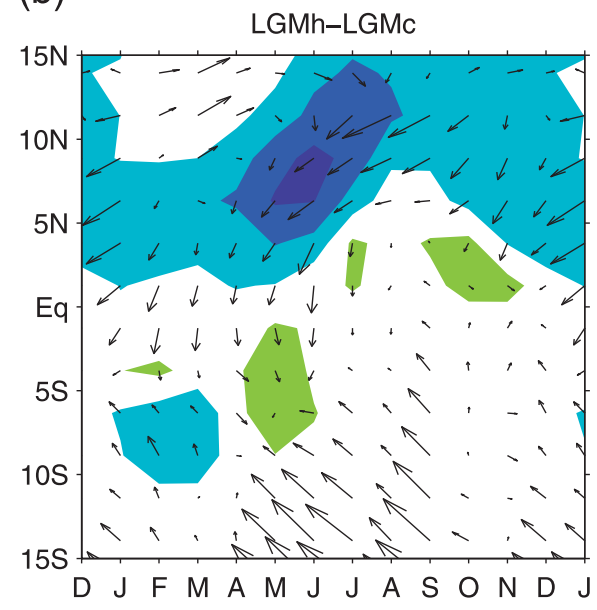

(d)

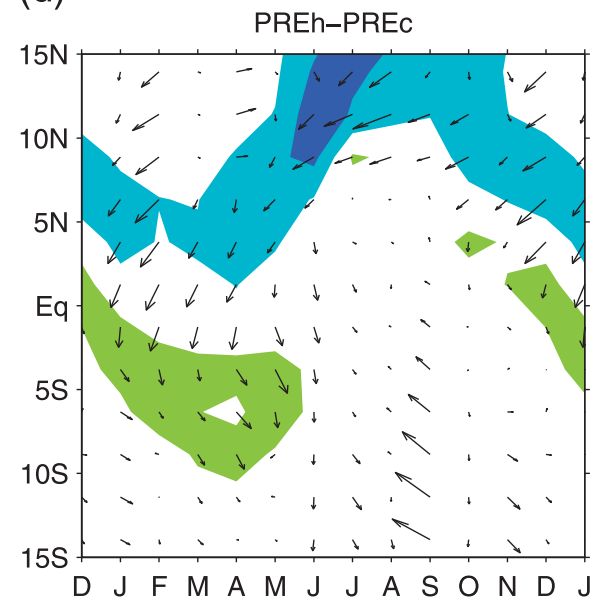

(e)
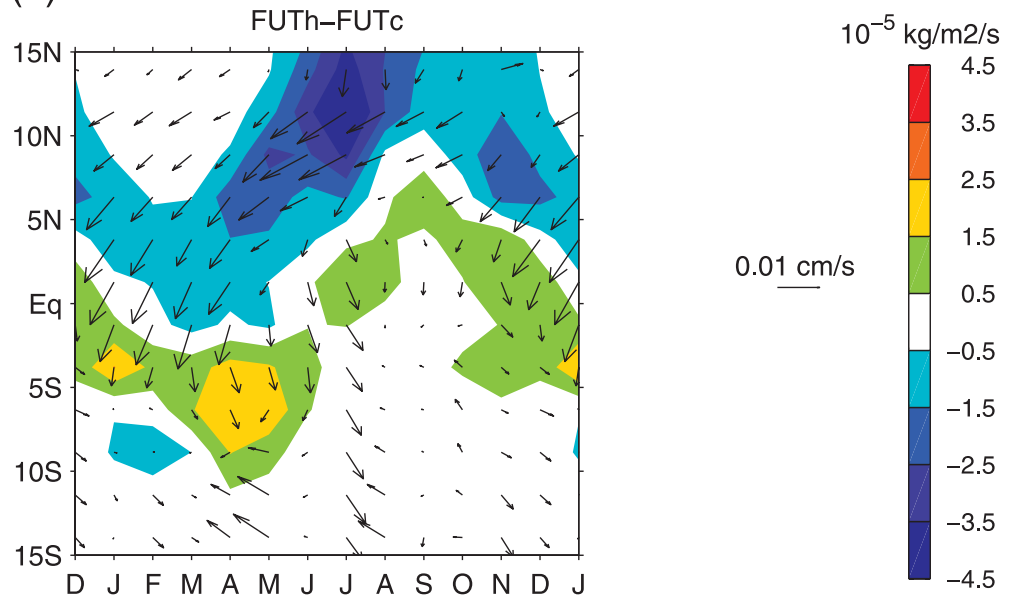

FIG. 14. Time-latitude sections of anomalous precipitation (colors, zero contour omitted) and anomalous surface wind stress (vectors) averaged between $120^{\circ}$ and $80^{\circ} \mathrm{W}$ in response to the anomalous freshwater input in the five sensitivity experiments. (a) LIGh-LIGc, (b) LGMh-LGMc, (c) HOLh-HOLc, (d) PREh-PREc, (e) FUTh-FUTc. 
(a)

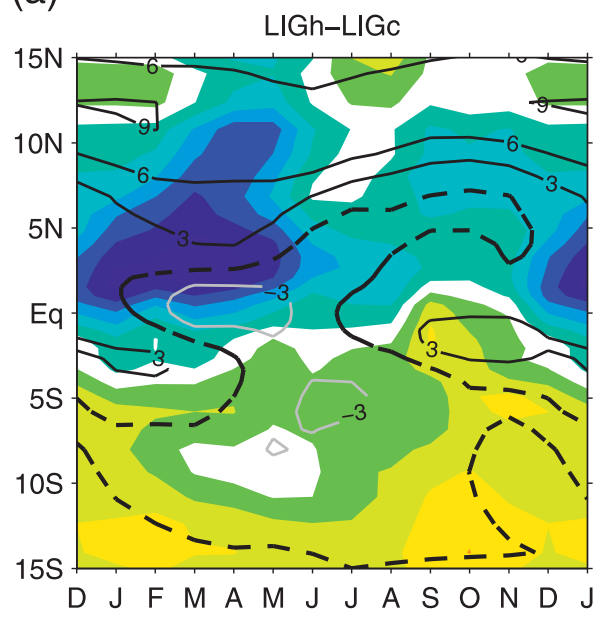

(c)

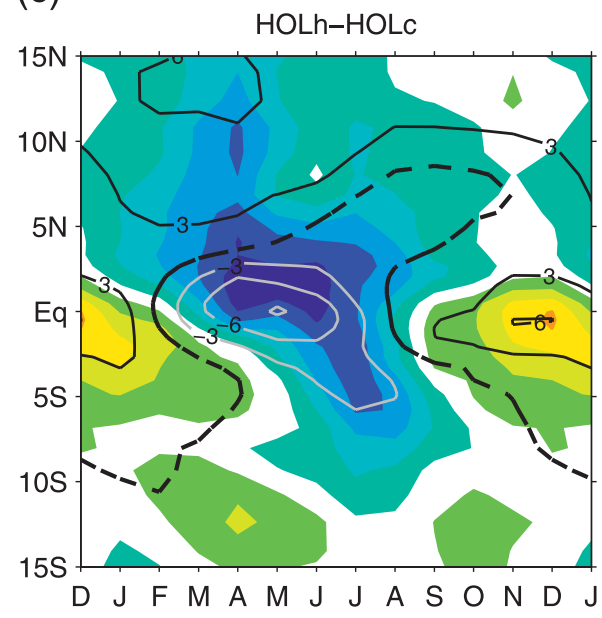

(b)

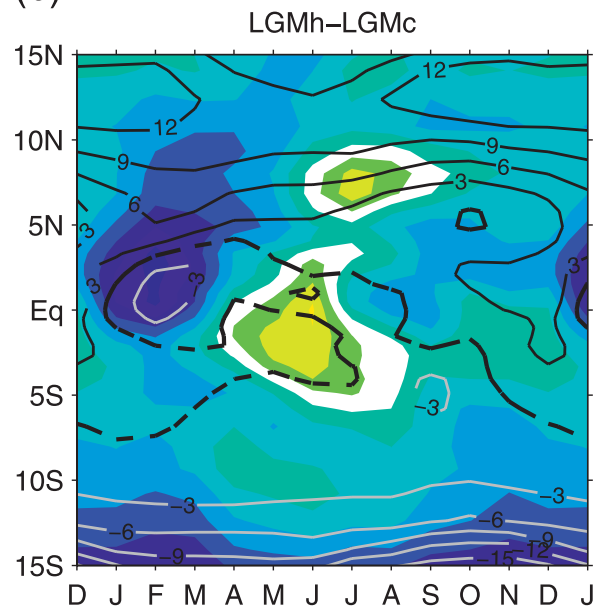

(d)

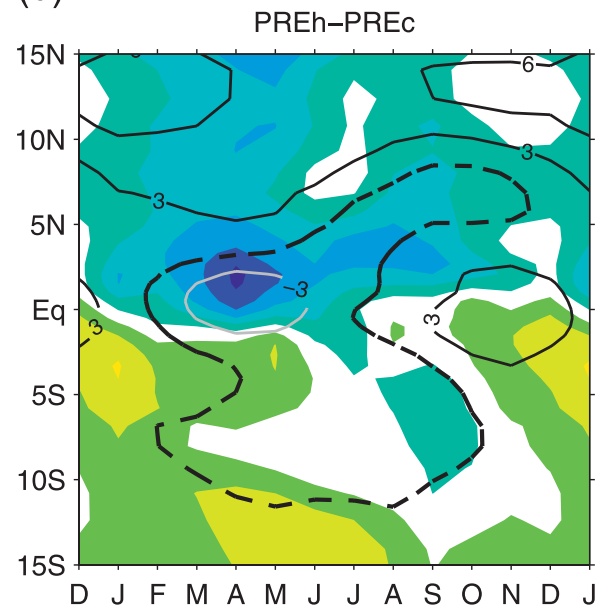

(e)

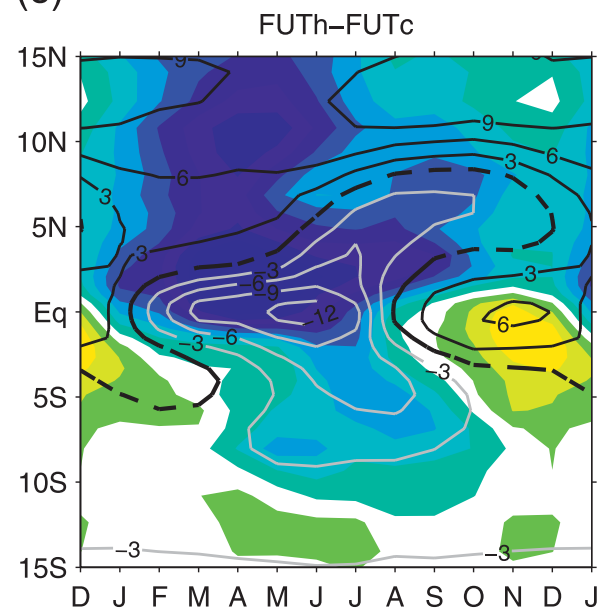

$\mathrm{K}$

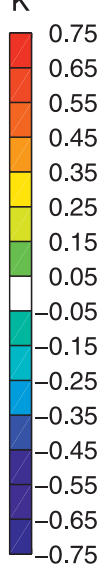

FIG. 15. Time-latitude section of anomalous SST (colors, zero contour omitted) and anomalous depth of the $20^{\circ} \mathrm{C}$ isotherm (contour interval is $3 \mathrm{~m}$; black contours, positive; gray contours, negative; zero contour, dashed) averaged between $120^{\circ}$ and $80^{\circ} \mathrm{W}$ in response to the anomalous freshwater input in the five sensitivity experiments. (a) LIGh - LIGc, (b) LGMh - LGMc, (c) HOLh - HOLc, (d) PREh - PREc, (e) FUTh - FUTc. 


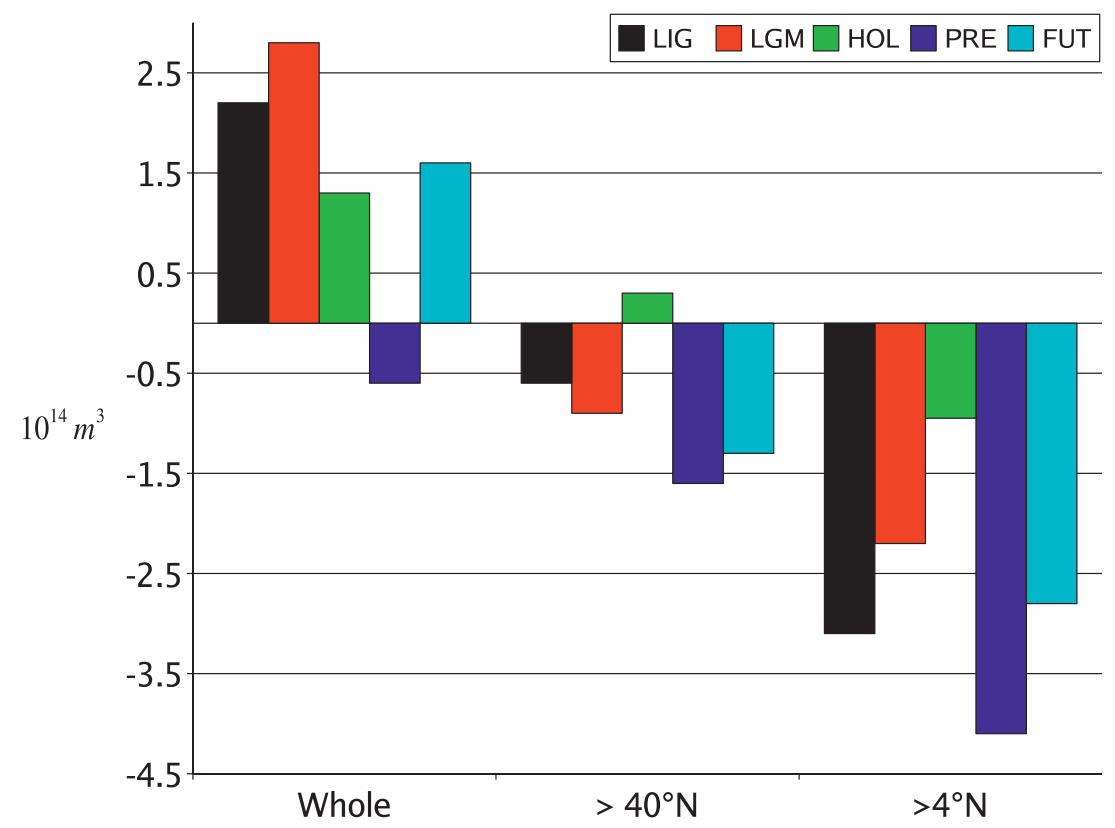

FIG. 16. Differences between hosing and control simulations for the cumulative surface freshwater in the Atlantic $\left(\mathrm{Sv} \mathrm{yr}^{-1}\right)$, computed over $250 \mathrm{yr}$, in terms of net budget at different latitude bands in the Atlantic minus the perturbation (calving; see Fig. 5). LIGh LIGc (black), LGMh - LGMc (red), HOLh - HOLc (green), PREh - PREc (blue), and FUTh - FUTc (cyan).

Timmermann (2007), this increase in the global freshwater budget over the Atlantic does not necessarily mean that the southward shift of the ITCZ is a positive feedback for the AMOC. The global freshwater budget of the Atlantic is actually not the main driver of the AMOC, which appears to be more sensitive to the freshwater budget near its convection sites (Rahmstorf 1996; Roche et al. 2009). Indeed, Vellinga et al. (2002) show that the decrease in precipitation over the subtropical gyre of the NA has more influence than the decrease in the total freshwater budget over the Atlantic. In the present experiments, the total freshwater anomalies over the Atlantic, north of $4^{\circ} \mathrm{N}$, is smaller than the freshwater perturbation (Fig. 16). This implies a relative reduction in the freshwater forcing that reaches $4.0 \times 10^{14} \mathrm{~m}^{3}$ in PREh or $52 \%$ of the freshwater perturbation. It is larger than $25 \%$ in the other simulations except for HOL, where it is only $13 \%$. We therefore conclude that although we have not performed any dedicated sensitivity experiments as in Vellinga et al. (2002) or Krebs and Timmermann (2007), the ITCZ shift in our experiments may also play the role of a negative feedback for the AMOC, increasing its stability. The intensity of this feedback (as measured by the difference between the total freshwater anomalies north of $4^{\circ} \mathrm{N}$ and the freshwater perturbation, see Fig. 16) appears to be smaller in HOLh and not in LGMh. This shows that the instability of the AMOC for LGM climate conditions is not related to a difference in this feedback, but rather to a different configuration of its convection sites, located south of the GIS Ridge, as argued by Ganopolski and Rahmstorf (2001).

\section{Conclusions}

In this study we evaluate the impact of different climate conditions on the freshwater input in the ocean. Our analyses focus on the climatic impact of such freshwater inputs. For this purpose we compare five pairs of 250-yr simulations where different amounts of freshwater have been either added in the NA or not. The amount of freshwater depends on the climatic conditions. It varies between $7.3 \times 10^{14}$ and $13.6 \times 10^{14} \mathrm{~m}^{3}$, depending on the simulation. In most simulations the freshwater amount is computed by the model through a crude parameterization that mimics the ice sheet melting. We have compared these hosing experiments with the corresponding simulations without freshwater input. The hosing and control simulations were integrated concurrently from rest and then differenced. The different climates that we explore are the last interglacial, the Last Glacial Maximum, the mid-Holocene, the preindustrial, and the future $\left(2 \times \mathrm{CO}_{2}\right.$ scenario). We find that the simulated freshwater input resulting from Greenland melting (related to 
surface heat budget) is larger during LIG than for $2 \times$ $\mathrm{CO}_{2}$, illustrating the importance of the very large increase in summer insolation during LIG, for which the warming in summer over Greenland is even larger than the one resulting from $\mathrm{CO}_{2}$ doubling in this model. Moreover, we show that despite similarities between the different periods, the freshwater affects the AMOC slightly differently as well as the characteristics of surface temperature and precipitation.

Our results can be summarized as follows. First, we show that the final AMOC response to freshwater input is not linear with the volume of this input over the length of the simulation and is sensitive to the background state. In particular, we confirm that the AMOC is more sensitive to freshwater input under LGM conditions than under warmer climates. We have analyzed the energetic adjustment of the climate system in response to the associated decrease in oceanic heat transport. We find a complex picture where changes in the atmospheric heat transport and radiative budget modifications play crucial roles. In particular, it appears that the response of the convection sites to the freshwater forcing is critical for sea ice cover. A collapse of convection leads to a reduction in the vertical heat exchange in the ocean and favors the formation of sea ice [process (ii) of the introduction]. Together with the reduction of the ocean heat transport, this leads to a large-scale cooling over the Northern Hemisphere.

Additionally, and rather counterintuitively, in all simulations but LGMh, a warming pattern along the eastern coast of Greenland is found in response to the freshwater input in the NA. This warming is associated with changes in the surface winds in response to the large-scale cooling of the Northern Hemisphere. This atmospheric circulation change modifies the sea ice cover regionally and reduces it along the east coast of Greenland. This sea ice melting leads to the observed warming because of the induced large albedo difference and changes in heat flux exchanges between the ocean and atmosphere, related with the insulator effect of sea ice.

A regional warming pattern associated with a largescale Northern Hemisphere cooling resulting from a freshwater input in the NA has also been found in several OAGCM in the case of a $0.1 \mathrm{~Sv}$ "water hosing" experiments (Stouffer et al. 2006). This response was attributed to a northward migration of the convection sites, since the freshwater perturbation was not applied north of $70^{\circ} \mathrm{N}$, leading to a sea ice melting north of $70^{\circ} \mathrm{N}$ in the NA [resulting from process (ii)], which warms the climate through the albedo feedback. In our experiments, the warming pattern was not associated with a shift in convection site, but instead, as in Saenko et al. (2007), to a change in wind stress. This change in wind is associated to a modification in the large-scale sea level pressure, which resembles the Aleutian low-Icelandic low (AL-IL) pattern described by Honda et al. (2001). Recently, Msadek and Frankignoul (2008), using the same OAGCM, found that the Atlantic Multidecadal Oscillation (related to the AMOC) exerts a weak positive feedback on the atmosphere through a slight forcing of the second mode of variability over the NA, the east Atlantic pattern. This regional mode of variability is associated with the large-scale AL-IL (R. Msadek 2009, personal communication), which supports our results.

Finally, we study the precipitation response to the anomalous freshwater input, mainly in the tropics. We find a southward shift of the ITCZ in the Atlantic and east Pacific, whatever the baseline climatic conditions. The intensity of this shift in the Atlantic depends on the intensity of the mean cooling north of $25^{\circ} \mathrm{N}$. This is explained by the mechanisms leading to this shift. It involves a meridional atmospheric bridge that transfers the cooling signal from the high northern latitudes to the tropics. The ITCZ shift generally propagates to the eastern Pacific Ocean, together with most ingredients of surface and subsurface equatorial dynamics. However, there are slight differences among the different climates. The response in precipitation is strongest above the relatively warm ocean in FUTh, while the meridional SST dipole in the tropical Pacific is most visible in LIGh, where the mean state is most symmetrical across the equator, consistent with Okajima et al. (2003). The thermodynamical response in LGMh is still poorly understood. More generally, note that in some hosing experiments the AMOC is completely "off," while it is only reduced in others. This might be a reason for nonlinearity in the climatic response (Kageyama et al. 2009).

The implication of the present study is that even under different climatic conditions and for different freshwater inputs in the NA (depending on these climatic conditions), the climatic responses to these inputs share very similar patterns in the Atlantic-east Pacific sector (cooling in the NA, a shift of the ITCZ, and a local warming pattern). In this respect, reconstruction of past climates is probably useful to test the models and evaluate their ability to reproduce rapid climate changes like Heinrich events. However, modeling the associated mean climate of the LGM appears to be a necessary step to provide a correct comparison with proxy data, because the response is quantitatively different from the other climates. An important caveat of the present study is the AMOC bias in PREc, which has been associated to an incorrect freshwater budget in the NA (Swingedouw et al. 2007b). A higher atmospheric resolution of the same model (Marti et al. 2009) has shown that part of this bias can be 
corrected with a better representation of the wind stress field. In the light of the present study, this may have implications for the global warming projections using this new model, which will be analyzed in future work. Analysis of the sensitivity of paleoclimate experiments to freshwater forcing using other models would help to validate the robustness of the nonlinearity of the climate system response to AMOC changes. This will be an important topic for the third phase of the Paleoclimate Modeling Intercomparison Project (Otto-Bliesner et al. 2009).

Acknowledgments. We thank Charline Marzin, Olivier Marti, and Christophe Cassou for interesting and constructive discussions. We are grateful to three anonymous reviewers for helpful advice and comments. The authors wish to acknowledge use of the Ferret software for analysis and graphics in this paper and the help of Patrick Brockmann for the use of this software. The simulations were run on the NEC SX8 of the CCRT. This work is a contribution to two ANR Blanche Projects (2005-09), PICC and IDEGLACE.

\section{REFERENCES}

Adler, R., and Coauthors, 2003: The Version 2 Global Precipitation Climatology Project (GPCP) Monthly Precipitation Analysis (1979-present). J. Hydrometeor., 4, 1147-1167.

Berger, A., 1978: Long-term variations of caloric insolation resulting from the earth's orbital elements. Quat. Res., 9, 139-167.

Bitz, C. M., J. C. H. Chiang, W. Cheng, and J. J. Barsugli, 2007: Rates of thermohaline recovery from freshwater pulses in modern, Last Glacial Maximum, and greenhouse warming climates Geophys. Res. Lett., 34, L07708, doi:10.1029/2006GL029237.

Bjerknes, J., 1964: Atlantic air-sea interaction. Advances in Geophysics, Vol. 10, Academic Press, 1-82.

_ 1966: A possible response of the atmospheric Hadley circulation to equatorial anomalies of ocean temperature. Tellus, 18, 820-829.

_ 1969: Atmospheric teleconnections from the equatorial $\mathrm{Pa}-$ cific. Mon. Wea. Rev., 97, 163-172.

Blanke, B., and P. Delecluse, 1993: Variability of the tropical Atlantic Ocean simulated by a general circulation model with two different mixed layer physics. J. Phys. Oceanogr., 23, 1363-1388.

Bond, G. C., and R. Lotti, 1995: Iceberg discharges into the North Atlantic on millennial time scales during the last glaciation. Science, 267, 1005-1010.

- , and Coauthors, 2001: Persistent solar influence on North Atlantic climate during the Holocene. Science, 294, 2130-2136.

Boning, C. W., F. O. Bryan, W. R. Holland, and R. Doscher, 1996: Deep-water formation and meridional overturning in a highresolution model of the North Atlantic. J. Phys. Oceanogr., 26, 1142-1164.

Braconnot, P., and Coauthors, 2007: Results of PMIP2 coupled simulations of the Mid-Holocene and Last Glacial MaximumPart 1: Experiments and large-scale features. Climate Past, 3, 261-277.

_ C. Marzin, L. Gregoire, E. Mosquet, and O. Marti, 2008: Monsoon response to changes in Earth's orbital parameters:
Comparisons between simulations of the Eemian and of the Holocene. Climate Past, 4, 281-294.

Charbit, S., D. Paillard, and G. Ramstein, 2008: Amount of $\mathrm{CO}_{2}$ emissions irreversibly leading to the total melting of Greenland. Geophys. Res. Lett., 35, L12503, doi:10.1029/2008GL033472.

Chiang, J. C. H., and C. M. Bitz, 2005: Influence of high latitude ice cover on the marine Intertropical Convergence Zone. Climate Dyn., 25, 477-496.

— W. Cheng, and C. M. Bitz, 2008: Fast teleconnections to the tropical Atlantic sector from Atlantic thermohaline adjustment. Geophys. Res. Lett., 35, L07704, doi:10.1029/2008GL033292.

Clarke, G. K. C., D. W. Leverington, J. T. Teller, and A. S. Dyke, 2004: Paleohydraulics of the last outburst flood from glacial Lake Agassiz and the 8200 BP cold event. Quat. Sci. Rev., 23, 389-407.

Cuffey, K. M., and S. J. Marshall, 2000: Substantial contribution to sea level rise during the last interglacial from the Greenland ice sheet. Nature, 404, 591-594.

De Boer, A. M., and N. Nof, 2004: The exhaust valve of the North Atlantic. J. Climate, 17, 417-422.

Duplessy, J. C., N. J. Shackleton, R. Fairbanks, L. Labeyrie, D. Oppo, and N. Kallel, 1988: Deep water source variation during the last climatic cycle and their impact on the global deep water circulation. Paleoceanography, 3, 343-360.

EPICA Community Members, and Coauthors, 2006: One-to-one coupling of glacial climate variability in Greenland and Antarctica. Nature, 444, 195-198.

Fichefet, T., and M. A. M. Maqueda, 1997: Sensitivity of a global sea ice model to the treatment of ice thermodynamics and dynamics. J. Geophys. Res., 102, 2609-2612.

, C. Poncin, H. Goosse, P. Huybrechts, I. Janssens, and H. L. Treut, 2003: Implications of changes in freshwater flux from the Greenland ice sheet for the climate of the 21st century. Geophys. Res. Lett., 30, 1911, doi:10.1029/2003GL017826.

Ganachaud, A., and C. Wunsch, 2000: Improved estimates of global ocean circulation, heat transport and mixing from hydrographic data. Nature, 408, 453-457.

Ganopolski, A., and S. Rahmstorf, 2001: Rapid changes of glacial climate simulated in a coupled climate model. Nature, 409, 153-158.

Garcin, Y., A. Vincens, D. Williamson, G. Buchet, and J. Guiot, 2007: Abrupt resumption of the African Monsoon at the Younger Dryas-Holocene climatic transition. Quat. Sci. Rev., 26, 690-704.

Gent, P. R., and J. C. Mc Williams, 1990: Isopycnal mixing in ocean circulation models. J. Phys. Oceanogr., 20, 150-155.

Heinrich, H., 1988: Origin and consequence of cyclic ice rafting in the northeast Atlantic Ocean during the past 130,000 years. Quat. Res., 29, 142-152.

Honda, M., H. Nakamura, J. Ukita, I. Kousaka, and K. Takeuchi, 2001: Interannual seesaw between the Aleutian and Icelandic lows. Part I: Seasonal dependence and life cycle. J. Climate, 14, 1029-1042.

— , Y. Kushnir, H. Nakamura, S. Yamane, and S. E. Zebiak, 2005: Formation, mechanisms, and predictability of the Aleutian-Icelandic low seesaw in ensemble AGCM simulations. J. Climate, 18, 1423-1434.

Hourdin, F., and Coauthors, 2006: The LMDZ4 general circulation model: Climate performance and sensitivity to parameterized physics with emphasis on tropical convection. Climate Dyn., 27, 787-813

Hu, A., B. L. Otto-Bliesner, G. A. Meehl, W. Han, C. Morrill, E. C. Brady, and B. Briegleb, 2008: Response of thermohaline 
circulation to freshwater forcing under present day and LGM conditions. J. Climate, 21, 2239-2258.

Huybrechts, P., and J. de Wolde, 1999: The dynamic response of the Greenland and Antarctic ice sheets to multiple-century climatic warming. J. Climate, 12, 2169-2188.

Jungclaus, J. H., H. Haak, M. Esch, E. Roeckner, and J. Marotzke, 2006: Will Greenland melting halt the thermohaline circulation? Geophys. Res. Lett., 33, L17708, doi:10.1029/2006GL026815.

Kageyama, M., J. Mignot, D. Swingedouw, C. Marzin, R. Alkama, and O. Marti, 2009: Glacial climate sensitivity to different states of the Atlantic Meridional Overturning Circulation: Results from the IPSL model. Climate Past Discuss., 5, 10551107.

Kawase, M., 1987: Establishment of deep ocean circulation driven by deep-water production. J. Phys. Oceanogr., 17, 2294-2317.

Krebs, U., and A. Timmermann, 2007: Tropical air-sea interactions accelerate the recovery of the Atlantic Meridional Overturning Circulation after a major shutdown. J. Climate, 20, 4940-4956.

Krinner, G. N., and Coauthors, 2005: A dynamic global vegetation model for studies of the coupled atmosphere-biosphere system. Global Biogeochem. Cycles, 19, GB1015, doi:10.1029/ 2003GB002199.

Leduc, G., L. Vidal, K. Tachikawa, F. Rostek, C. Sonzogni, L. Beaufort, and E. Bard, 2007: Moisture transport across Central America as a positive feedback on abrupt climatic changes. Nature, 445, 908-911.

Levitus, S., 1982: Climatological Atlas of the World Ocean. NOAA Prof. Paper 13, 173 pp. and 17 microfiche.

Lynch-Stieglitz, J., and Coauthors, 2007: Atlantic meridional overturning circulation during the last glacial maximum. Science, 316, 66-69.

MacAyeal, D., 1993: Binge/purge oscillations of the Laurentide ice sheet as a cause of the North Atlantic's Heinrich events. Paleoceanography, 8, 775-784.

Madec, G., P. Delecluse, M. Imbard, and C. Levy, 1998: OPA 8.1 ocean general circulation model reference manual. Institut Pierre-Simon Laplace (IPSL) Note du Pole de modélisation $11,91 \mathrm{pp}$.

Manabe, S., and R. J. Stouffer, 1988: Two stable equilibria of a coupled ocean-atmosphere model. J. Climate, 1, 841-866.

Marti, O., and Coauthors, 2009: Key features of the IPSL ocean atmosphere model and its sensitivity to atmospheric resolution. Climate Dyn., in press.

McManus, J., R. Francois, J.-M. Gherardi, L. Keigwin, and S. Brown-Leger, 2004: Collapse and rapid resumption of Atlantic meridional circulation linked to deglacial climate changes. Nature, 428, 834-837.

Meehl, G. A., G. J. Boer, C. Covey, M. Latif, and R. J. Stouffer, 2000: The Coupled Model Intercomparison Project (CMIP). Bull. Amer. Meteor. Soc., 81, 313-318.

Mikolajewicz, U., M. Vizcaino, J. Jungclaus, and G. Schurgers, 2007: Effect of ice sheet interactions in anthropogenic climate change simulations. Geophys. Res. Lett., 34, L18706, doi:10.1029/ 2007GL031173.

Msadek, R., and C. Frankignoul, 2008: Atlantic multidecadal oceanic variability and its influence on the atmosphere in a climate model. Climate Dyn., 33, 45-62, doi:10.1007/s00382008-0452-0.

North Greenland Ice Core Project Members, 2004: High-resolution climate record of Northern Hemisphere climate extending into the last interglacial period. Nature, 431, 147-151.
Okajima, H., S.-P. Xie, and A. Numaguti, 2003: Interhemispheric coherence of tropical climate variability: Effect of climatological ITCZ. J. Meteor. Soc. Japan, 81, 1371-1386.

Otto-Bliesner, B. L., S. Marshall, J. Overpeck, G. Miller, and A. Hu, 2006: Simulating arctic climate warmth and icefield retreat in the last interglaciation. Science, 311, 1751-1753.

- , S. Joussaume, P. Braconnot, S. P. Harrison, and A. Abe-Ouchi, 2009: Modeling and data syntheses of past climates. Eos, Trans. Amer. Geophys. Union, 90, doi:10.1029/2009EO110013.

Pahnke, K., J. P. Sachs, L. Keigwin, A. Timmermann, and S. P. Xie, 2007: Eastern tropical Pacific hydrologic changes during the past 27,000 years from $\mathrm{D} / \mathrm{H}$ ratios in alkenones. Paleoceanography, 22, PA4214, doi:10.1029/2007PA001468.

Peterson, L. C., G. H. Haug, K. A. Hughen, and U. Rohl, 2000: Rapid changes in the hydrologic cycle of the tropical North Atlantic during the last glacial. Science, 290, 1947-1951.

Rahmstorf, S., 1996: On the freshwater forcing and transport of the Atlantic thermohaline circulation. Climate Dyn., 12, 799-811.

Rayner, N. A., D. E. Parker, E. B. Horton, C. K. Folland, L. V. Alexander, D. P. Rowell, E. C. Kent, and A. Kaplan, 2003: Global analyses of sea surface temperature, sea ice, and night marine air temperature since the late nineteenth century. J. Geophys. Res., 108, 4407, doi:10.1029/2002JD002670.

Ridley, J. K., P. Huybrechts, J. M. Gregory, and J. A. Lowe, 2005 : Elimination of the Greenland ice sheet in a high $\mathrm{CO}_{2}$ climate. J. Climate, 18, 3409-3427.

Roche, D. M., A. P. Wiersma, and H. Renssen, 2009: A systematic study of the impact of freshwater pulses with respect to different geographical locations. Climate Dyn., doi:10.1007/s00382-009$0578-8$, in press.

Roullet, G., and G. Madec, 2000: Salt conservation, free surface and varying levels: A new formulation for ocean general circulation models. J. Geophys. Res., 23, 927-942.

Saenko, O. A., A. J. Weaver, D. Y. Robitaille, and G. M. Flato, 2007: Warming of the subpolar Atlantic triggered by freshwater discharge at the continental boundary. Geophys. Res. Lett., 34, L15604, doi:10.1029/2007GL030674.

Schiller, A., U. Mikolajewicz, and R. Voss, 1997: The stability of the North Atlantic thermohaline circulation in a coupled ocean-atmosphere general circulation model. Climate Dyn., 13, 325-347.

Schneider, B., M. Latif, and A. Schmittner, 2007: Evaluation of different methods to assess model projections of the future evolution of the Atlantic meridional overturning circulation. J. Climate, 20, 2121-2132.

Shaffrey, L., and R. Sutton, 2006: Bjerknes compensation and the decadal variability of the energy transports in a coupled climate model. J. Climate, 19, 1167-1181.

Solomon, S., D. Qin, M. Manning, M. Marquis, K. Averyt, M. M. B. Tignor, H. L. Miller Jr., and Z. Chen, Eds., 2007: Climate Change 2007: The Physical Science Basis. Cambridge University Press, $996 \mathrm{pp}$.

Stocker, T. F., 1998: Climate change-The seesaw effect. Science, 282, 61 .

Stoll, H. M., D. Vance, and A. Arevalos, 2007: Records of the Nd isotope composition of seawater from the Bay of Bengal: Implications for the impact of Northern Hemisphere cooling on ITCZ movement. Earth Planet. Sci. Lett., 255, 213-228.

Stouffer, R. J., and Coauthors, 2006: Investigating the causes of the response of the thermohaline circulation to past and future climate changes. J. Climate, 19, 1365-1387.

Swingedouw, D., P. Braconnot, and O. Marti, 2006: Sensitivity of the Atlantic Meridional Overturning Circulation to the melting 
from northern glaciers in climate change experiments. Geophys. Res. Lett., 33, L07711, doi:10.1029/2006GL025765.

— - — P. Delecluse, E. Guilyardi, and O. Marti, 2007a: Quantifying the AMOC feedbacks during a 2xCO2 stabilization experiment with land-ice melting. Climate Dyn., 29, 521-534.

,,,$--- \ldots$, and,$- 2007 \mathrm{~b}$ : The impact of global freshwater forcing on the thermohaline circulation: Adjustment of North Atlantic convection sites in a CGCM. Climate Dyn., 28, 291-305.

Talley, L. D., J. L. Reid, and P. E. Robbins, 2003: Data-based meridional overturning streamfunctions for the global ocean. J. Climate, 16, 3213-3226.

Timmermann, A., and Coauthors, 2007: The influence of a weakening of the Atlantic meridional overturning circulation on ENSO. J. Climate, 19, 4899-4919.

Uppala, S., and Coauthors, 2005: The ERA-40 re-analysis. Quart. J. Roy. Meteor. Soc., 131, 2961-3012.

Valcke, S., D. Declat, R. Redler, H. Ritzdorf, T. Schoenemeyer, and R. Vogelsang, 2004: Proceedings of the 6th International Meeting, VOL. 1: High Performance Computing for Computational Science. Universidad Politecnica de Valencia.
Vellinga, M., and R. A. Wood, 2002: Global climatic impacts of a collapse of the Atlantic thermohaline circulation. Climatic Change, 54, 251-267.

,-- , and J. M. Gregory, 2002: Processes governing the recovery of a perturbed thermohaline circulation in HadCM3. J. Climate, 15, 764-780.

Weber, S., and Coauthors, 2007: The modern and glacial overturning circulation in the Atlantic ocean in PMIP coupled model simulations. Climate Past, 3, 51-64.

Wu, L., C. Li, C. Yang, and S.-P. Xie, 2007: Global teleconnections in response to a shutdown of the Atlantic meridional overturning circulation. J. Climate, 21, 3002-3019.

Xie, S. P., 1999: A dynamic ocean-atmosphere model of the tropical Atlantic decadal variability. J. Climate, 12, 64-70.

-, Y. Okumura, T. Miyama, and A. Timmermann, 2008: Influences of Atlantic climate change of the tropical Pacific via the Central American Isthmus. J. Climate, 21, 3914-3928.

Yang, H. J., and Z. Y. Liu, 2005: Tropical-extratropical climate interaction as revealed in idealized coupled climate model experiments. Climate Dyn., 24, 863-879.

Zhang, R., and T. L. Delworth, 2005: Simulated tropical response to a substantial weakening of the Atlantic thermohaline circulation. J. Climate, 18, 1853-1860. 